\title{
Cognitive dimensions of learning in children with problems in attention, learning and memory
}

Joni Holmes $^{1 *+}$, Jacalyn Guy $^{1+}$, Rogier A. Kievit ${ }^{1}$, Annie Bryant ${ }^{2}$, the CALM Team ${ }^{1} \&$ Susan E. Gathercole ${ }^{3}$

${ }^{1}$ MRC Cognition \& Brain Sciences Unit, University of Cambridge, UK

${ }^{2}$ Department of Clinical Psychology, Faculty of Medicine and Health Sciences, University of East Anglia, Norwich, UK

${ }^{3}$ Department of Psychiatry, University of Cambridge, UK

*Corresponding author

+ Joint first authors

\section{Author Note}

Portions of these findings were presented as a poster at the 7th Annual Flux Congress in New York, New York, United States, and as talks at: the Better Learning Conference in Kiev, Ukraine; the Centre for Developmental Disorders Public Lecture in Durham. UK; the Beyond Working Memory conferences in Melbourne and Perth, Australia. The authors do not have any conflicts of interest to disclose.

All correspondence for this article should be addressed to Joni Holmes, MRC Cognition and Brain Sciences Unit, University of Cambridge, 15 Chaucer Road, CB2 7EE, Cambridge, United Kingdom. Email: joni.holmes@mrc-cbu.cam.ac.uk. 


\begin{abstract}
A data-driven, transdiagnostic approach was employed to identify the cognitive dimensions linked with learning in a large mixed group of children recognised to have problems in the areas of attention, learning and memory by a health or education practitioner $(\mathrm{N}=805)$. The children completed a battery of cognitive assessments tapping phonological processing, information processing speed, short-term and working memory, and executive functions, and attainments in reading, spelling, vocabulary and maths. Data reduction methods identified three cognitive dimensions of phonological processing, processing speed and executive function for the sample as a whole. This model was comparable for children with and without ADHD. The severity of learning difficulties in literacy was linked to phonological processing skills, and in maths to executive control. Associations between cognition and learning were broadly comparable across subgroups, but learning-related problems were more strongly linked to executive skills and processing speed in children with ADHD than without ADHD. The results establish that domain-specific cognitive pathways to learning distinguish a large heterogeneous population of struggling learners. They also indicate that robust cognitive skills may be vital in compensating for the adverse impact of ADHD behaviours on learning.
\end{abstract}

Keywords: Cognition, learning difficulties, transdiagnostic, ADHD, reading, maths 


\section{Educational Impact and Implications Statement}

This study identified a set of learning-related cognitive abilities differentiating a large mixed population of children who are struggling to learn. Rather than taking the standard approach of distinguishing groups of children based on their particular areas of learning difficulty, the data were analysed from the entire sample as a whole to identify the cognitive dimensions related to learning. Close links were found between phonological processing skills and literacy achievement, and between executive skills and mathematical abilities. Deficits in these skills predicted the severity and nature of learning difficulties. Assessing these skills early in the school years can help identify children at risk of educational underachievement (A. G. Bishop \& League, 2006; Catts, Fey, Zhang, \& Tomblin, 2001; Gathercole, Brown, \& Pickering, 2003), and provide a vital step towards timely and targeted support. Phonological and language-based interventions are highly effective for children with weak phonological processing skills (Bowyer-Crane et al., 2008; M. J. Snowling \& Hulme, 2012). Programs designed to develop executive skills have been less successful in improving behavioural and educational outcomes (Cortese et al., 2015; Kassai, Futo, Demetrovics, \& Takacs, 2019). A classroom management approach that provides new ways for the child to access learning material and supports the development of self-help strategies ${ }^{1}$ may help mitigate these problems, and is already widely recommended for children with $\mathrm{ADHD}^{2}$. The finding that learning depends even more strongly on cognitive skills in children with ADHD, possibly to compensate for the impact of behavioural disruptions in learning settings, underscores the potential value of this approach for this population in particular.

\footnotetext{
${ }^{1}$ https://www.understood.org/en/school-learning/partnering-with-childs-school/instructional-strategies/at-aglance-classroom-accommodations-for-executive-functioning-issues

${ }^{2} \mathrm{http}: / /$ smhp.psych.ucla.edu/pdfdocs/attention/attention.pdf), https://education.wm.edu/centers/ttac/documents/packets/adhd.pdf
} 


\section{Introduction}

Several children in a typical classroom experience persistent learning difficulties that are likely to reflect weak cognitive skills. The standard approach adopted by educational systems and researchers alike is to classify children and tailor support according to the particular area (e.g., reading or mathematics) in which they are experiencing problems. This pragmatic, classification-based approach has considerable strengths. However, many children with relatively mild problems go undetected, and the needs of others with complex learning difficulties and co-occurring disorders often go unaddressed. To better capture the needs of the common struggling learner, this study adopted an alternative method inspired by the transdiagnostic approach that seeks to identify symptom dimensions rather than categories of disorder. This approach is central to the NIHR Research Domains Criteria (RDoC) framework for research (Cuthbert \& Insel, 2013) and is highly appropriate for the study of heterogeneous populations of children with cognitive developmental disorders (Casey, Oliveri, \& Insel, 2014). A large, heterogeneous sample of children was recruited with problems that were defined functionally rather than through strict inclusionary and exclusionary criteria: each child was identified by either an educational or health professional as experiencing difficulties related to cognition and learning. A data-driven approach was used to identify dimensions of cognitive skills critical for learning within this population.

\section{Learning Problems}

Unexplained learning difficulties are common. Between 14 and 30\% of school-aged children in the United Kingdom and the United States require additional support for learning (Department for Education, 2018; National Center for Education Statistics, 2019). The prevalence of reading difficulties is estimated at 16\% (Catts, Compton, Tomblin, \& Bridges, 2012), $7 \%$ of the school population are considered to be dyslexic (Peterson \& Pennington, 2012), and 3\% of children have reading comprehension problems (Lervåg \& Aukrust, 2010; M. Snowling, Cain, Nation, \& Oakhill, 2009). Approximately $10 \%$ of children have a developmental language disorder (Laasonen et al., 2018) and mathematical difficulties are present in between 3 and 13\% of children (Geary, 2013; Landerl \& Moll, 2010). Long-term outcomes for individuals with learning problems include early disengagement from education (Balfanz, Herzog, \& Mac Iver, 2007), low rates of employment (Bynner, Foudouli, \& Parsons, 2005; De Beer, Engels, Heerkens, \& van der Klink, 2014) and increased risks of mental health 
and behavioural problems (Emerson \& Hatton, 2007). The need to minimise the risks of continued educational underachievement and the associated societal and economic costs is great: poor academic progress has many causes that can interact and cascade over time (e.g. Masten \& Cicchetti, 2010).

Children often experience problems in multiple aspects of learning and behaviour. Cooccurring reading difficulties are present in between 17 and $70 \%$ of children with mathematical learning problems, and corresponding rates of mathematical difficulties in children identified with reading problems are 11 to 56\% (Barbaresi, Katusic, Colligan, Weaver, \& Jacobsen, 2005; Dirks, Spyer, van Lieshout, \& de Sonneville, 2008; Moll, Kunze, Neuhoff, Bruder, \& SchulteKörne, 2014; von Aster, Schweiter, \& Weinhold Zulauf, 2007). Many children with learning difficulties also meet the diagnostic criteria for Attention Deficit and Hyperactivity Disorder (ADHD), a psychiatric disorder based on observations of elevated levels of inattention, hyperactivity and impulsivity (DSM-5; American Psychiatric Association, 2013). In a US population study, $44 \%$ of children with ADHD had learning difficulties and $42 \%$ of those with a specific learning disability met criteria for ADHD (Pastor \& Reuben, 2008).

\section{Cognitive Origins of Learning Problems}

There is an extensive body of evidence concerning the cognitive skills associated with academic abilities within the typically-developing school population, clinical populations, and in children with pronounced difficulties in specific aspects of learning. Most of the research has focussed on the skills contributing to children's literacy and mathematical abilities. The key outcomes and some of the most important persisting theoretical debates are described below.

\section{Reading}

Processing Speed. Fluent reading requires rapid processing of incoming information (e.g. Cohen, Dehaene, Vinckier, Jobert, \& Montavont, 2008; Dehaene, Cohen, Sigman, \& Vinckier, 2005; Pastor \& Reuben, 2008). Children with reading problems are relatively slow on rapid automated naming tasks used to measure the speed of verbal processing (Catts, Gillispie, Leonard, Kail, \& Miller, 2002). It has been suggested that rather than being central to reading difficulties (Kail \& Hall, 1994), slow verbal processing speed may be a consequence of phonological processing difficulties (Bonifacci \& Snowling, 2008; Patel, Snowling, \& de Jong, 2004). Nonverbal processing speed deficits are less common in reading difficulties (Bonifacci \& Snowling, 2008; Gooch, Snowling, \& Hulme, 2012)) and have been suggested to reflect co- 
occurring attentional problems (McGrath et al., 2011; Willcutt et al., 2010) or low IQ (Bonifacci \& Snowling, 2008).

Phonological processing. Children with specific reading difficulties have deficits in a range of phonological skills including nonword reading, phonological awareness and rapid naming (Herrmann, Matyas, \& Pratt, 2006; Johnson \& Goswami, 2010; Kudo, Lussier, \& Swanson, 2015; Melby-Lervåg, Lyster, \& Hulme, 2012; Metsala, Stanovich, \& Brown, 1998; Swanson \& Jerman, 2006). This evidence provides the foundation for the hypothesis that reading difficulties arise from phonological processing limitations that interfere with the use of phonological representations to guide reading. These limitations include problems in phonological awareness, the ability to reflect on and manipulate covertly the constituent sounds of words. Limitations in phonological awareness are suggested to impair the acquisition and application of spelling-sound correspondences that are critical for decoding and spelling words (D. V. M. Bishop \& Snowling, 2004; Clayton, West, Sears, Hulme, \& Lervåg, 2019; Perfetti, 2007).

Although close links between phonological processing and reading development are evident, they are not yet fully understood. Phonological awareness contributes to reading development, but it also benefits from both reading instruction and exposure to text during reading acquisition (Huettig, Lachmann, Reis, \& Petersson, 2018; Wagner, Torgesen, \& Rashotte, 1994). Recent evidence suggests that such reciprocal effects between cognitive abilities, as well as between cognitive abilities and school outcomes, are likely ubiquitous (Kievit, Hofman, \& Nation, 2019; Peng \& Kievit, 2019). Studies of formerly illiterate adults whose very low levels of phonological awareness at the beginning of reading instruction closely tracked their later success in learning to read support this (Morais, 1987; Morais \& Kolinsky, 2005). However, it is also evident that phonological deficits cannot explain all forms of reading difficulties. Children with developmental surface dyslexia have no impairments in applying letter-sound correspondences to decode and spell words, but struggle in learning words with orthographically irregular sound patterns (Castles \& Friedmann, 2014). Other children have no difficulties with single word reading but have impairments in the comprehension of written text (Cain, Oakhill, \& Lemmon, 2004; Nation, 1999).

Short-term and working memory. Measures of verbal short-term memory (STM) such as digit span and nonword repetition are strongly associated with reading abilities (Gathercole et al., 2003; Kudo et al., 2015; Peng \& Fuchs, 2016; Swanson, Zheng, \& Jerman, 2009). The causality 
of these links has been widely debated. One suggestion is that STM is critical for the maintenance and assembly of phonological segments in the process of word identification (Preßler, Könen, Hasselhorn, \& Krajewski, 2014). Others have argued that there are no causal links between STM and reading and that their association is mediated by a common contribution of phonological processing skills (Melby-Lervåg, Lervåg, et al., 2012; MelbyLervåg, Lyster, et al., 2012).

Working memory (WM) is a more complex cognitive system that combines short-term storage with the attentional capacity to integrate temporary representations of recently processed information with sources of long-term knowledge (Allen, Hitch, Mate, \& Baddeley, 2012; Baddeley, 2010). Verbal measures of WM are highly correlated with reading. This has been proposed to reflect the role played by WM in integrating multiple sources of knowledge including phonological representations from STM and lexical-semantic knowledge from longterm memory (Cantor \& Engle, 1993; Swanson \& Ashbaker, 2000). Analyses of reading comprehension indicate that while WM is important, the abilities to draw inferences from text and monitor comprehension are also critical (Cain et al., 2004). The extent to which the link between WM and reading reflects a direct causal association has not gone without challenge. For example, findings from Nation (1999) suggest that verbal WM deficits are a consequence of, rather than a contributor to, the language processing problems of children with poor reading comprehension.

Executive functions. Problems in the high-level control of cognitive resources tapped by executive function tasks have been reported in children with reading difficulties (Booth, Boyle, \& Kelly, 2010; Carretti, Borella, Cornoldi, \& De Beni, 2009; Yeniad, Malda, Mesman, van IJzendoorn, \& Pieper, 2013). This is perhaps unsurprising: reading involves the coordination of multiple processes including attending to visual word forms, decoding words, retrieving semantic and lexical information, and integrating the syntactic and semantic context of a passage of text. Selective attention has been linked to the visual pattern recognition element of reading, while the flexible deployment of attention is thought to support the decoding of words and the extraction of their meaning (e.g. Cartwright, 2012). Inhibitory control has been proposed to be vital for the suppression of irrelevant word meanings and details when reading complex sentences containing words with multiple meanings (De Beni \& Palladino, 2000; Kieffer, Vukovic, \& Berry, 2013). Both inhibitory control and the ability to switch attention have been associated with the development of reading skills, and in particular with the transition from early phonological to more advanced orthographic reading processes (Booth et 
al., 2010; Follmer, 2018). Fluid intelligence is a broad measure of the flexible cognitive resources available to solve new problems that is considered a critical part of the broad executive control system (Duncan, 2013). While linked to reading ability, the possibility that low fluid intelligence plays a causal role in developmental impairments of reading has been widely dismissed (Siegel, 1994; Stanovich, 1991; Stuebing et al., 2002).

\section{Mathematics}

Processing Speed. Geary (1993) and Gersten, Jordan, \& Flojo (2005) have suggested that processing speed supports fluent counting, which in turn allows problems and answers to be bound in WM before entering long-term memory. This binding of problems and answers supports the development of a network of basic arithmetic facts in long-term memory that can be used to rapidly retrieve answers as mathematical skills develop (Hamann \& Ashcraft, 1985; Kaye, 1986). Consistent with this, children with mathematical difficulties are less likely to use direct memory retrieval to solve arithmetic questions (Bull \& Johnston, 1997; Geary, Brown, \& Samaranayake, 1991; Mussolin \& Noel, 2008), count more slowly and inaccurately than children with age-appropriate maths abilities (Bull \& Johnston, 1997; Geary, Bow-Thomas, \& Yao, 1992), and have weak or incomplete networks of number facts in long-term memory (Geary et al., 1991; Hitch \& McAuley, 1991). Faster processing speed may also help prevent the decay and loss of task-critical information such as the arithmetic problem the child is attempting to solve, or the interim calculations that are necessary steps in more complex mathematical calculations (Holloway \& Ansari, 2008).

Phonological Processing. The phonological representation hypothesis proposes that solving calculation problems requires encoding and maintaining phonological representations in STM, and retrieving phonological codes from long-term memory (Hecht, Torgesen, Wagner, \& Rashotte, 2001; Simmons \& Singleton, 2008; Vukovic \& Lesaux, 2013). However, the impact of phonological processing on mathematical development is not without debate. It has been suggested that the manipulation of phonological information influences mathematical achievement by supporting number-word sequence learning (Krajewski \& Schneider, 2009) and that deficits in phonological processing are related to early calculation difficulties (Hecht et al., 2001). Other evidence indicates that phonological processing deficits are only present in children who have difficulties in both reading and mathematics because phonological processing problems are closely related to reading skills (Fuchs et al., 2005; Landerl \& Moll, 2010). 
Short-term and Working Memory. STM and WM may support the storage of problem information and both the storage and retrieval of partial results for simple and complex mathematical tasks (De Smedt, Swillen, Verschaffel, \& Ghesquière, 2009; Passolunghi, Mammarella, \& Altoè, 2008; Peng, Namkung, Barnes, \& Sun, 2016). Geary (1993, 2003) proposed that these memory systems enable children to remember number bonds to commit to a network of arithmetic facts in long-term memory. Mathematical abilities are typically more closely associated with visuo-spatial than verbal aspects of STM and WM (Holmes, Adams, \& Hamilton, 2008; Li \& Geary, 2013; Meyer, Salimpoor, Wu, Geary, \& Menon, 2010). The specificity of this deficit is most evident in children with specific impairments in mathematics but not in reading (Child, Cirino, Fletcher, Willcutt, \& Fuchs, 2019; Cirino, Child, \& Macdonald, 2018; Szucs, Devine, Soltesz, Nobes, \& Gabriel, 2013; Willcutt et al., 2013).

Executive Functions. Mathematical abilities are associated with many aspects of executive functioning in typically-developing individuals and are often impaired in those with mathematical difficulties (Friso-van den Bos, van der Ven, Kroesbergen, \& van Luit, 2013; Johnson \& Goswami, 2010; Peng \& Fuchs, 2016; Peng, Wang, \& Namkung, 2018; Swanson \& Jerman, 2006; Yeniad et al., 2013). Inhibitory control and attentional switching are two areas of deficit common in groups with mathematical problems (Bull \& Scerif, 2001; Landerl \& Kölle, 2009; Rotzer et al., 2009; Szucs et al., 2013). These skills have been suggested to play important roles in supporting the selection of solution strategies and the suppression of nonoptimal approaches (Bull \& Lee, 2014). Fluid intelligence is more strongly associated with attainments in mathematics than reading (Blair, Gamson, Thorne, \& Baker, 2005; Geary, 2011). This may reflect the high cognitive loads involved in learning and acquiring increasingly complex concepts and sets of rules as mathematical education progresses, and also the greater reliance on abilities to represent and manipulate information in the nonverbal domain at multiple stages of mathematical learning (Peng \& Kievit, 2019; Peng et al., 2018; Young, Levine, \& Mix, 2018).

\section{A New Approach to Learning Problems}

Until the last decade, most studies of specific learning difficulties employed relatively small numbers of participants with narrowly-defined problems. Individuals were typically grouped according to the presence or absence of one or more disorders, for example ADHD and / or reading difficulties (Marzocchi et al., 2008; Rucklidge \& Tannock, 2002; Willcutt et al., 2001). Selection was based on strict inclusionary and exclusionary criteria applied in community- 
based screening or school populations, or in children recruited from clinical services (Geurts, van der Oord, \& Crone, 2006; Jordan, Hanich, \& Kaplan, 2003; McLean \& Hitch, 1999).

Group-based studies such as these have shaped current understanding of the cognitive deficits underlying specific learning difficulties. Although invaluable, this methodological approach has substantial limitations. First, groups are often recruited according to stringent inclusion criteria that are arbitrarily set and inconsistently applied across studies (Stuebing, Fletcher, Branum-Martin, Francis, \& VanDerHeyden, 2012; Tolar, Fuchs, Fletcher, Fuchs, \& Hamlett, 2014). For example, selection criteria for children with reading difficulties ranges from reading scores of -1 to -2.5 SD below the population mean (Barbot et al., 2016; Catts, Adlof, \& Ellis, 2006). As a consequence, children included in one study may be excluded from others, yielding evidence that may not be generalisable to the broad, mixed population of children with learning-related difficulties (Coghill \& Sonuga-Barke, 2012; Kotov et al., 2017). Second, within-group heterogeneity is often disregarded and goes undetected in group studies, with statistical analysis focussing on differences at the group level that mask the high levels of variability found in the cognitive characteristics of children within each group. For example, performance on executive function tasks is highly variable in children with ADHD (Castellanos et al., 2005; Nigg, Willcutt, Doyle, \& Sonuga-Barke, 2005) and the profiles of cognitive impairment are often markedly different in children with reading difficulties (Nation, Clarke, $\&$ Snowling, 2002). A further limitation is that group designs typically obscure cross-disorder homogeneity, even though symptoms frequently co-occur across different conditions. For example, WM problems are common across children with difficulties in reading and mathematics, as well as those with ADHD and autistic spectrum disorder (ASD; Duinmeijer, de Jong, \& Scheper, 2012; Gathercole \& Alloway, 2008; Holmes et al., 2008; Loe \& Feldman, 2007; Rommelse, Geurts, Franke, Buitelaar, \& Hartman, 2011).

Concerns about these issues of symptom heterogeneity and high levels of comorbidity within classification systems for adult psychological and psychiatric disorders have led to a shift towards using symptom dimensions instead of unitary diagnostic labels (Cuthbert \& Insel, 2013; Owen, 2014). This approach allows treatment to be tailored to the constellation of needs of the individual rather than to an ill-fitting diagnostic label. This transdiagnostic approach has been most extensively applied to adult psychiatric conditions including depression, anxiety and psychosis (e.g., R.-Mercier, Masson, Bussières, \& Cellard, 2018; Reininghaus et al., 2019; Titov et al., 2011). 
The value of extending a dimensional, transdiagnostic approach to neurodevelopmental disorders has been widely recognised (Casey et al., 2014; E. J. S. SonugaBarke \& Coghill, 2014; E. J. S. Sonuga-Barke, Cortese, Fairchild, \& Stringaris, 2016; Zhao \& Castellanos, 2016). However, most studies espousing this approach have employed group designs comparing the cognitive or behavioural characteristics of groups with traditionallydefined disorders such as reading difficulties, maths difficulties, ADHD or ASD with typicallydeveloping individuals (de Jong, Bitter, van Setten, \& Marinus, 2009; Hobson, 2014; Karalunas et al., 2014; R.-Mercier et al., 2018; Willcutt et al., 2013). To date, dimensions have rarely been assessed over broader mixed populations of children whose problems may not conform to current diagnostic categories.

\section{The Present Study}

This study adopts a more radical transdiagnostic approach with the aim of identifying the dimensions of cognitive impairment that characterise children with mild to moderate learningrelated difficulties. This broad group includes not only pupils who fit canonical categories of learning disorders, but also those with multiple co-occurring problems that extend beyond learning, and others with milder impairments that do not meet diagnostic thresholds but nonetheless compromise academic progress.

A critical step in designing the study was to establish an appropriate sampling frame for the recruitment of a wide and representative range of participants from this target population (Cuthbert \& Insel, 2013). The standard group-based approach of employing arbitrary inclusionary and exclusionary criteria would necessarily distort the range of children included. An alternative, functionally-defined, approach was adopted: practitioners in education or health referred to the study children who they observed to have difficulties in one or more aspects of attention, learning and memory. A research clinic for these children was established as part of the larger Centre for Attention Learning and Memory (CALM) project. As part of the sampling strategy, children exhibiting high levels of ADHD symptoms were recruited. Many of these children had a diagnosis of ADHD, while others had a possible diagnosis confirmed by an ADHD nurse. No exclusionary criteria were applied except for uncorrected sensory problems, known neurological or genetic disorders, or speaking a language other than English as a native language. In total, data from 805 children were analysed to identify the main dimensions of cognitive skills and to chart links between these cognitive dimensions and learning. Of the sample, approximately $40 \%$ had diagnoses of one or more disorders related to learning, 
behaviour or mental health. A third of the sample were recognised as having ADHD (see Table $1)$.

The choice of cognitive assessments was guided by measures identified by previous research as having robust links to learning. A latent variable approach was used to identify the primary cognitive dimensions of the sample, in line with data-driven approaches recently adopted in transdiagnostic, dimensional studies in psychiatry (e.g., Kotov et al., 2017; R.Mercier et al., 2018; Reininghaus et al., 2019). A major advantage of this approach is that it side-steps debates about which of two different measures sharing common variance represents the core deficit (e.g. phonological processing or verbal STM in reading difficulties). Instead, it simply identifies the major sources of variance across all measures in a dataset: in this case, the broad dimensions of cognitive skills that may or may not contribute to learning. Using this approach, we set out to answer the following three questions.

\section{What are the broad cognitive dimensions underpinning individual cognitive abilities within} this sample?

The test battery assessed six aspects of cognition known to be strongly associated to at least one aspect of learning (literacy or mathematics): phonological processing, processing speed, working memory, executive functions, attention, and nonverbal reasoning. It was anticipated that the dimensional structure of the data might take one of three possible forms. First, the tasks might fit neatly within the conventional neuropsychological taxonomy of cognitive assessments, with dimensions corresponding to phonological processing, STM, WM, executive functions, and fluid intelligence. Second, the dimensions might crosscut these task-based dimensions and instead fractionate according to domain (verbal vs visuo-spatial). Third, a hybrid model may be favoured that combines domain-specific factors with a domain-general factor spanning all tasks requiring higher-level cognitive control.

2. How are the cognitive dimensions linked with reading, spelling, mathematics and vocabulary?

Reading and language abilities, both in the general population and in groups of typical and atypical learners, are closely associated with phonological skills (e.g. D. V. M. Bishop \& Snowling, 2004; Melby-Lervåg \& Hulme, 2010). In contrast, mathematical abilities are more strongly linked with visuo-spatial skills and executive functions (Peng et al., 2018), particularly when children with comorbid reading difficulties are excluded (e.g. Szucs et al., 2013). 
Whether the same dimensions differentiate a large mixed sample of children with learningrelated difficulties is unknown. If the same factors influence learning as in other typical and atypical populations, it would be expected that reading abilities and vocabulary would be strongly linked with phonological processing and verbal aspects of STM and WM, while mathematical abilities would show the strongest links with tasks requiring executive control.

\section{Are the same cognitive dimensions linked with learning in children with and without ADHD?}

The large number of children with ADHD participating in the study provided a unique opportunity to test whether the cognitive dimensions linked to learning are equivalent for children with and without a diagnosis of this disorder. Learning problems are present in almost half of children with ADHD (Pastor \& Reuben, 2008). It has been proposed that this cooccurrence reflects a shared genetic vulnerability to impairments in two different neurocognitive pathways (Castellanos et al., 2005; E. Sonuga-Barke, Bitsakou, \& Thompson, 2010; E. J. S. Sonuga-Barke, 2002; Solanto, Arnsten, \& Castellanos, 2001). By this account, the first pathway consists of cool executive functions that control performance regardless of affective context (Zelazo \& Müller, 2002). This supports the set of cognitive skills responsible for phonological processing, STM, WM, executive functions, and fluid intelligence. Behaviourally, poor functioning in this pathway is believed to manifest as high levels of inattention, a defining symptom of ADHD that is often present in children with learning difficulties (Pastor \& Reuben, 2008). The second pathway supports hot executive functions in which cognitive control is modulated by emotional valence. Weaknesses in this pathway are suggested to give rise to delay aversion and to underlie hyperactive and impulsive behaviours that form part of the basis for a clinical diagnosis of ADHD (Castellanos et al., 2002).

The current study aimed to test this double-deficit model of ADHD. If the model holds true, children with ADHD should be distinguished by the same cognitive dimensions as the sample as a whole, and their links to learning should be the same. It is already known that the cognitive profiles of the two populations have many common characteristics. Children with ADHD have impairments in WM (e.g. Kofler et al., 2019) and deficits in a range of executive functions including response inhibition (e.g. Tenenbaum et al., 2019), attentional switching (e.g. Irwin, Kofler, Soto, \& Groves, 2019), and planning (e.g. Patros, Tarle, Alderson, Lea, \& Arrington, 2019). Holmes et al. (2014) reported that the profiles of children with ADHD and those with poor WM (which is closely associated with learning difficulties) were indistinguishable in terms of academic performance and cognitive skills. 
Alternatively, learning may be compromised by disturbances in the emotionallymediated cognitive pathway (hot executive functions) in children with ADHD. It seems plausible that impulsive and hyperactive behaviours in structured classroom activities might reduce opportunities for successful learning. Consistent with this position, higher levels of ADHD symptoms have been found to be associated with more adverse educational outcomes (Gremillion \& Martel, 2012; McGrath et al., 2011). This might be especially marked in mathematical learning, which requires sustained periods of concentration with minimal external support (e.g., in mental arithmetic). The attentional burden of learning to read may also be high, although it could be offset by external supports provided by the continued visibility of text, the availability of activated semantic representations of the content of the text that can scaffold reading and, for younger children in particular, pictorial support. If the behavioural hypothesis is correct, learning will be less dependent on core cognitive skills in children with than without ADHD.

\section{Method}

\section{Participants}

This study includes all children attending the CALM clinic between February 2014 and December 2018. The children were referred by practitioners in education and health (teachers, special needs coordinators, specialist teachers, educational psychologists, paediatricians, child psychiatrists and psychologists, and speech and language therapists). Children were eligible to take part if they were aged between 5 and 18 years $(\mathrm{M}=9.48, \mathrm{SD}=2.38)$ and had been recognised by a referrer as having problems in one or more of the following areas: attention, memory, language, maths, and / or literacy. Exclusion criteria were significant uncorrected visual or hearing problems, pre-existing genetic or neurological conditions for which cognitive difficulties are known possible symptoms, and not being a native English speaker.

Referrers passed a study information pack to families with children who they judged in their professional opinion to have problems in the areas of attention, learning and / or memory. Families then sent an expression of interest form to CALM if they wanted to participate. The research team then contacted the referrer to discuss the child's problems and diagnostic status, and to check their eligibility for the study. If the child met the inclusion criteria, the family was sent an appointment letter to attend the clinic for an assessment. Families were reminded of their appointment by telephone the day before the assessment, and at this time, they were asked whether their child had any diagnosed conditions. 
The number of children referred to CALM was 914 (291 females). Twenty-five families did not attend their clinic appointment and a further 77 children did not meet the inclusion criteria. A total of 812 (255 females) were assessed, with data excluded for three children who were non-native English speakers, three children who refused to complete the majority of the tests, and one child with a neurological condition that prevented completion of the assessments (see Figure 1). Reports of diagnosed disorders from the referrer and family at the time of referral are summarised in Table 1. The final sample for analysis includes 805 children (253 female), yielding power of $.999 / 0.992$ to detect a correlation of .2 with $\alpha=.05$ and .001 , respectively. Data from a subset of approximately 600 participants aged 8 years and over (8+) were analysed separately in a second set of analyses. Power for this subgroup was .998/.951 to detect a .2 correlation with $\alpha=.05$ and .001 , respectively.

\section{Insert Figure 1}

\section{Materials and procedures}

Parents or caregivers completed questionnaires regarding the child's behaviour, communication skills, family history, and mental health. Children participated in a four-hour assessment of cognitive and learning skills on a one-to-one basis. They were invited to provide an optional saliva sample for later genetic analysis and to attend a separate session for an optional MRI brain scan. A report summarising performance on the cognitive and behavioural tasks was sent to the referrer to guide ongoing support for the child. A full description of assessments administered in the CALM clinic is provided in the study protocol paper (Holmes, Bryant, Gathercole, \& Team, 2019). Analysis in the present study was performed on the cognitive and learning measures.

\section{Insert Table 1}

\section{Cognition}

\section{Phonological Processing}

Two subtests from the Phonological Assessment Battery ( PhAB, Frederickson, Frith, \& Reason, 1997) were administered: Rapid Naming and Alliteration. Raw scores from both subtests were converted to standard scores $(\mathrm{M}=100, \mathrm{SD}=15)$. The Children's Test of Nonword Repetition (CNRep,Gathercole \& Baddeley, 1996)) was also administered: raw 
scores were converted to standard scores. The CNRep was introduced after the first 300 children to attend the clinic had been tested.

\section{Processing Speed}

The Motor Speed and Visual Scanning subtests of the Delis Kaplan Executive Function System (DK-EFS, Delis, Kaplan, Kramer, Delis, \& Kramer, 2001) were administered. Completion times were converted to scaled scores $(\mathrm{M}=10, \mathrm{SD}=3)$. The Simple Reaction Time subtest of the Test of Everyday Attention for Children 2 (TEA-Ch2, Manly et al., 2016) was also administered. Reaction time in seconds was recorded and converted to a scaled score.

\section{Short-term (STM) and Working Memory (WM)}

Four span tasks from the Automated Working Memory Assessment (AWMA, Alloway, 2007)) were administered: Digit Recall (verbal STM), Dot Matrix (visuo-spatial STM), Backward Digit Recall (verbal WM), and Mr X (visuo-spatial WM). Trials correct were converted to standard scores for each task $(M=100, S D=15)$. A following instructions task (Gathercole, Durling, Evans, Jeffcock, \& Stone, 2008; Jaroslawska, Gathercole, Logie, \& Holmes, 2016) was also administered. This experimental task required children to follow increasingly long instruction sequences. Total raw scores were tallied. To account for age, a regression analysis was conducted predicting raw scores from age. Residual scores therefore represent the difference between each participant's observed and age-predicted score. These were included in all analyses.

\section{Episodic Memory}

The Stories subtest of the Children's Memory Scale (M. Cohen, 1997) was used to assess language skills and episodic memory. The measure of delayed recall was used: raw scores were converted to scaled scores $(\mathrm{M}=10, \mathrm{SD}=3)$.

\section{Executive Function}

The Tower and Trail Making subtests of the DKEFS (Delis et al., 2001) were administered to children aged 8 years and above to measure planning and switching abilities respectively. For the Tower task, total achievement scores were converted to scaled scores $(\mathrm{M}=10, \mathrm{SD}=3)$; for the Trails Number-Letter Sequencing task completion times were converted to scaled scores $(\mathrm{M}=10, \mathrm{SD}=3)$. The DKEFS subtests were not administered to the first 60 children attending the CALM clinic. 
The Matrix Reasoning subtest of the Wechsler Abbreviated Scales of Intelligence II (WASI-II, Wechsler, 2011) was used to index general reasoning. Trials correct were converted to $\mathrm{T}$-scores $(\mathrm{M}=50, \mathrm{SD}=10)$.

\section{Attention}

Children younger than 8 years completed three tasks from the TEA-Ch2 J (Manly et al., 2016). Those aged 8 and above completed the TEA-Ch2 A version (Manly et al., 2016) that includes more difficult adaptations of the same tasks plus one additional measure of switching. Sustained attention was measured using the Vigil $(8$ years +$)$ and Barking $(<8$ years $)$ subtests. Visual selective attention was assessed using the Hector Cancellation ( 8 years + ) and Balloon Hunt (<8years) subtests. Raw scores were converted to scaled scores. The switching task, Reds, Blues, Bags and Shoes, was administer only to those aged 8 years and over. Reaction times on switch trials were converted to scaled scores.

\section{Learning}

\section{Vocabulary}

The Peabody Picture Vocabulary Test (PPVT, Dunn \& Dunn, 2007) was administered. Raw scores were converted to standard scores $(\mathrm{M}=100, \mathrm{SD}=15)$.

\section{Spelling, Reading and Maths}

The Spelling, Word Reading and Numerical Operations subtests of the Wechsler Individual Achievement Test II (WIAT II, Wechsler, 2005) were given. Raw scores for all subtests were converted to standard scores $(M=100, S D=15)$. The Maths Fluency subtest of the Woodcock Johnson III Test of Achievement (WJ-III, Woodcock, McGrew, \& Mather, 2007) was administered to the first 68 children attending the clinic. Children had to respond accurately to as many simple maths problems as possible in three minutes. It was substituted for the WIAT II Numerical Operations test due to consistently low scores. To ensure these low scores reflected maths ability and were not caused by the time constraint in the WJ-III, the WIAT II subtest was introduced. A small number of children completed both maths assessments and there were no significant differences in performance across the tests (Holmes et al., 2019). 


\section{Results}

\section{Analysis Plan}

A statistical analysis plan for this study was pre-registered on the Open Science Framework (https://osf.io/jvm5t/). Two datasets were analysed separately. The first consists of all children $(\mathrm{N}=805)$ referred to CALM, and the second of a subset of children that includes all children aged 8+ years $(\mathrm{N}=566)$. This additional set of analyses for the older children was necessary because several of the executive function measures were not administered to the younger children due to age restrictions of the tests. The analyses were conducted on both datasets using $\mathrm{R}$ version 3.5.1 (R Core Team, 2018).

Exploratory factor analysis (EFA) was used to estimate the number of cognitive factors using R's Psych package (version 1.8.12, Revelle, 2018). The results from the EFA were used to fit confirmatory factor analyses (CFA) to the optimal model with the R Lavaan package (version 0.6-3, Rosseel, 2012). Cross-loadings were dropped in the CFA to simplify the model. Links between cognition and learning were explored through correlational analysis. Path model analyses with each learning outcome as the dependent variable and simultaneous entry of the cognitive factors were conducted to identify unique links with learning outcomes.

The pre-registered analysis plan states that measurement invariance will be used to determine whether the winning cognitive dimensions model fits subgroups within the sample. The original plan was to test whether the winning model fitted: a) children with and without an ADHD diagnosis; $b$ ) children with standard scores $<86$ on the learning measures compared to those with scores $>86$ (poor vs typical learners; c) children with and without an ADHD diagnosis within the subgroup of poor learners. On re-consideration the decision was made prior to the commencement of analysis to remove the comparisons made with poor learners in steps b) and c) from the manuscript. There were several reasons for this decision. First, on reflection it is not appropriate to use a criterion score to define individuals as poor learners when the entire sample was referred for learning-related cognitive difficulties. Second, any model derived from the whole sample would anyway consist predominantly of children who would be meet the criteria of being poor learners $(\mathrm{N}=601$ poor learners, $N=204$ typical learners). Its composition would therefore be strongly biased towards the poor learners. It also makes comparison c) of children with and without ADHD in the poor learner subgroup redundant, as this sample contains the majority of the whole sample for whom the results will 
have already been reported. However, for completeness, transparency and commitment to our preregistrations, all analyses as originally outlined have been performed and are reported in the supplementary materials (Supplementary Tables 16-23).

Measurement invariance (e.g.van de Schoot et al., 2013) was used to determine whether the optimal model of the cognitive dimensions derived for the whole sample fitted subgroups with and without ADHD. This was achieved using a number of steps, including manual modification of the model syntax as well as the measurementInvariance function as part of the semTools package (version 0.5.1; Jorgensen, Pornprasertmanit, Schoemann, \& Rosseel, 2018). Violations of metric /weak invariance were examined (i.e. equal factor loadings), as metric invariance is required to compare links between cognition and learning across groups. Where necessary, parameters were freed to meet metric invariance, guided by modification indices and as discussed in van de Schoot et al., 2013 or Steenkamp \& Baumgartner, 1998. Equality-constrained path models were used to test whether the hypothesized effects of cognitive performance on learning outcomes differed between children with and without ADHD.

\section{Insert Table 2}

\section{Descriptive statistics}

Performance on the cognitive and learning measures is reported for the whole sample and the $8+$ group in Table 2 . All scores were in the low average range (i.e. approximately 1 SD below age-typical scores) except for Mr X, Cancellation and vocabulary, where scores were within the age-typical range. Correlations between all measures for both groups are shown in Supplementary Tables 1 and 8.

\section{Cognitive dimensions for the whole sample}

\section{Exploratory Factor Analysis (EFA)}

A parallel analysis was conducted using the R Psych package (version 1.8.12) to determine the number of factors underlying performance on the cognitive measures. This uses a simulation of data with properties similar to the true data to compare the estimated number of factors to a permuted baseline (see: http://personality-project.org/r/psych/HowTo/factor.pdf). An oblimin (oblique) rotation, allowing the factors to be correlated, was used. For the subsequent confirmatory factor models fit indices outlined by Schermelleh-Engel, Moosbrugger, \& Müller (2003) were used. These included the root mean square error of approximation (RMSEA) and 
its confidence interval, the comparative fit index (CFI), and the standardized root mean squared residuals (SRMR). The $\chi 2$ test and its corresponding $p$ value were also reported. A good model fit was defined as RMSEA $<0.05$, CFI $>0.95$, SRMR $<0.05$, and an acceptable fit was defined as RMSEA 0.05-0.08, CFI 0.90-0.95, SRMR 0.05-.10.

A four-factor solution was indicated by the parallel analysis (see Supplementary Table $2)$, with a good fit to the data, $\chi 2(32)=53.39$, RMSEA $=0.029(90 \%$ confidence interval $[\mathrm{CI}]$ $=0.014,0.042), \mathrm{CFI}=0.989, \mathrm{RMSR}=0.02$. The measures loading most heavily on Factor 1 were Nonword Repetition and Digit Recall, both of which tap both phonological processing and verbal short-term memory. Measures of visuo-spatial STM and WM (Dot Matrix and Mr $\mathrm{X}$ ), verbal WM (Backward Digit Recall), visual selective attention (Cancellation), and Matrix Reasoning loaded most highly on Factor 2. These tasks have a common executive component. Less optimal features were that only a single variable loaded on Factor 3 (Rapid Naming) and that Factor 4 was difficult to interpret with reference to standard cognitive theory. A measure of sustained attention (Vigil), a processing speed measure (simple reaction time (SRT)), phonological measure (Alliteration) and two measures of memory, episodic (Delayed Story Recall) and working (Following Instructions) memory, loaded on to this factor, and they have little in common.

A likely explanation for the interpretational challenges of the four-factor model is that it overfits the data due to using the full sample for both the exploratory and confirmatory step (a decision made to maximize the data available, but with known risks of overfitting). We therefore also tested a three-factor solution (Supplementary Table 2). This model was a good fit, $\chi 2(42)=113.56$, RMSEA $=0.046(90 \%$ confidence interval $[\mathrm{CI}]=0.036,0.056), \mathrm{CFI}=$ $0.965, \mathrm{RMSR}=0.03$. Factor 1 included three variables that rely on processing verbal material: Nonword Repetition, Digit Recall and Delayed Story Recall. The measures loading most highly on Factor 2 were either speeded tasks (scores derived from RTs: SRT, Rapid Naming, Vigil), completed under time constraints (Cancellation) or contained features that meant faster responses could result in better performance (e.g. Alliteration, Following Instructions - faster recall $=$ less time for forgetting). The remaining measures known to draw on executive resources (Dot Matrix, Mr X, Matrix Reasoning, and Backward Digit Recall) loaded on the final factor. Based on considerations of cognitive theory, these factors are labelled 'phonological processing', 'processing speed', and 'executive function' respectively, in the analyses that follow. The three factor solution yielded a better fit based on measures that more substantially penalize complexity such as the BIC ( $\triangle \mathrm{BIC}=-6.742$ for the 4 vs 3 factor model), 
and the CFA comparison (below) suggested an only marginal preference for the simplified (cross-loadings removed) 4 factor versus 3 factor model $\Delta \chi^{2}=6.30, \Delta \mathrm{df}=2, p=.043$ ) despite the large sample. Most importantly, the factors and factor loadings were more theoretically interpretable in terms of cognitive theory. For these reasons, the three-factor model was taken forward for reasons of parsimony, theoretical interpretability and generalizability to other samples.

\section{Confirmatory Factor Analysis (CFA)}

A CFA was used to test the fit of the three-factor solution derived through the EFA. Fit statistics indicated that the three-factor model (Figure 2) was an acceptable fit to the data, $\chi^{2}(62)=247.76, p<.0001 ;$ RMSEA $=0.061 ; \mathrm{CFI}=0.90 ; \mathrm{SRMR}=0.047$. Resulting factor scores were extracted and saved using the Predict function in Lavaan to allow links between the cognitive dimensions and learning to be explored in a separate analysis (although a onestep analysis can be preferable, a two stage analysis was chosen for simplicity).

Insert Figure 2 here

\section{Links between cognition and learning for the whole sample}

To explore links between cognition and learning, scores for the three cognitive factors were correlated with each of the learning outcomes (see Supplementary Table 3 and Supplementary Figure 1). All measures of learning were significantly correlated to each of the cognitive dimensions ( $p<.05$ in each case). Measures of literacy (reading, spelling, and vocabulary) were most strongly related to phonological processing and mathematics was linked more closely to executive function. Links between the cognitive factors and learning measures were explored further in four multi-group path models in which the cognitive factor scores were entered simultaneously (see Supplementary Table 4 and Figure 3).

\section{Insert Figure 3 here}

In combination, the phonological, speed, and executive factors accounted for approximately $35 \%$ of the variance in reading, $24 \%$ in spelling, $39 \%$ in maths, and $36 \%$ in vocabulary scores. Reading, spelling and vocabulary were most strongly predicted by the phonological processing factor ( $p<.001$, in all cases). Reading was also significantly predicted by the speed factor $(p<.001)$. Mathematics was predicted solely by the executive function factor $(p<.001)$. 


\section{Children of all ages with and without ADHD}

To examine whether the three factor cognitive architecture of the whole sample generalizes to possible subgroups, a series of measurement invariance tests were conducted. These enable us to test whether the factor structure identified in the sample of 805 children is present, and similar, in identifiable subgroups within the sample. A two-step approach was used to determine whether the cognitive dimensions underlying individual cognitive abilities in the whole sample apply to children with ADHD $(\mathrm{N}=255 ; 107$ medicated $)$ and without ADHD (N $=550$ ), and to test whether the pathways to learning are the same or different between groups. Descriptive statistics for these groups are provided in Table 3. Both groups performed similarly across all cognitive tasks; scores were below average on all tasks for both groups, with the exception of the Cancellation, vocabulary and a test of visuo-spatial WM where scores were in the age-typical range for both groups. Children with ADHD scored significantly higher on Cancellation, Matrix Reasoning, and the reading and spelling tasks.

\section{Insert Table 3 here}

Tests of measurement invariance were conducted to determine whether the best-fitting three factor cognitive model identified for the whole sample showed similar model fit in children with and without ADHD. The parameters of the group level model were constrained in the following order. First, factor loadings were constrained to test for weak / metric invariance. If the models were invariant for the subgroups, the factors could be assumed to measure the same construct and links between these and learning outcomes could be compared between groups. Measurement invariance tests were evaluated using the $\chi 2$ likelihood ratio test and associated $p$ values to determine whether the application of increasing constraints worsened model fit (Putnick \& Bornstein, 2016). Where necessary, modification indices and fit indices from the measurementInvariance function (e.g. $\Delta \chi 2$ and $\Delta \mathrm{CFI}$ ) were used to indicate which parameters needed to be freed to meet partial metric / weak invariance, which had to be established for the pathways to learning to be compared between groups.

Configural invariance indices indicated that the 3-factor model was an acceptable fit for both groups, with exception of the CFI (see Supplementary Table 5). Tests of metric invariance revealed that a model which assumed identical factor loadings across groups did not worsen fit, $\Delta \chi^{2}=7.33, \Delta \mathrm{df}=10, p=.694$, indicating that metric invariance was met between the ADHD and non-ADHD groups. 
The ADHD group included both children with a diagnosis of ADHD $(n=198)$ and those who had seen a specialist ADHD nurse and were awaiting the final diagnostic consultation $(\mathrm{n}=57)$. Additional analyses were conducted between these groups. Descriptive statistics are provided in Supplementary Table 6. Both groups performed similarly across the cognitive and learning tasks, with the exception of Matrix Reasoning, reading and maths (see Supplementary Figure 2). In these cases, children with diagnosed ADHD performed significantly lower. To test whether including only children with a confirmed diagnosis affected the fit of the threefactor model to both ADHD and non-ADHD groups, metric invariance was tested again including only those with a diagnosis in the ADHD group. The models were still invariant, $\Delta \chi 2$ $=8.74, \Delta \mathrm{df}=10, p=.557$ (see Supplementary Table 7). Having established metric invariance between those with and without ADHD irrespective of whether the ADHD group included only those with a confirmed diagnosis or those with possible ADHD, the subsequent analyses were conducted including both those with confirmed and possible ADHD in the ADHD group.

The relationships between the three cognitive dimensions of phonological processing, executive function and processing speed and each of the learning outcomes were compared between the ADHD and non-ADHD groups. The cognitive dimensions were entered as predictors of reading, spelling, maths and vocabulary in four separate equality-constrained path models (standardized coefficients of paths estimated in the model between cognition and learning were compared for children with and without ADHD). These models, in which the effect of cognition on learning are treated as equal across groups, were compared to models in which the effects of cognition on learning are estimated individually. Interpretation of these comparisons are as follows. If the relationships are equal or highly similar across groups, the equality constrained models will fit the data better than freely estimated models due to greater parsimony. However, if the cognitive factors predict learning differentially across groups, the freely estimated models will provide a better fit to the data than the constrained models. The outcomes of these comparisons are shown in Table 4.

\section{Insert Table 4 here}

The freely estimated models for reading and maths provided a better fit than models in which the effects of cognitive factors on educational outcomes were assumed to be identical across groups (reading, $\Delta \chi^{2}(3)=11.85, p=.008$, mathematics, $\left.\Delta \chi^{2}(3)=12.31, p=.006\right)$. This indicates that the relationship between cognition and reading and maths differed in children with and without ADHD. For both groups, phonological processing significantly predicted 
reading (ADHD, $p=.002$, no ADHD, $p<.001$ ) but for children without ADHD, this prediction was stronger (ADHD, standardized beta: 0.329; no ADHD, standardized beta: 0.517). In contrast, processing speed predicted reading more strongly in children with ADHD (standardized beta: 0.571) than in children without ADHD (standardized beta: 0.152; see Supplementary Figure 3). Finally, executive functions were predictive of mathematics in both groups, but more strongly so in children with ADHD (standardized beta $=0.629$ ) than those without ADHD (standardized beta= 0.476).

The models for spelling and vocabulary did not differ significantly across groups (spelling, $\Delta \chi 2=7.03, p=.071$, vocabulary, $\Delta \chi 2=3.83, p=.281$ ). Both spelling and vocabulary were most strongly associated with phonological processing in children with and without ADHD (Spelling: ADHD, standardized beta: 0.318; no ADHD, standardized beta: 0.313; vocabulary: ADHD, standardized beta: 0.414; no ADHD, standardized beta: 0.398).

In summary, the three factor structure derived for the whole sample fit adequately in both children with and without ADHD, irrespective of whether the ADHD group was comprised of those with a confirmed diagnosis or possible diagnosis. For both those with and without ADHD, executive function predicted maths, and phonological processing predicted measures of literacy. The effect of executive function on maths was stronger for children with ADHD than those without ADHD. Speed was additionally linked to reading in children with ADHD, but the link between phonological processing and reading was weaker in these children than those without ADHD.

\section{Cognitive dimensions for children aged 8 years and over}

Children aged eight years and over $(\mathrm{N}=566)$ completed an additional set of executive function measures including two tests of switching (Trails and RBBS) and a measure of planning (Towers). Subtests of the Trails task included measures of visual scanning (cross out task) and motor speed (connecting dots as quickly as possible), increasing the number of speeded tasks included in these analyses. Data from the $8+$ group were analysed in order to establish how the broader set of executive function measures administered to this age group fit the dimensional structure of the data. The analyses completed for the whole sample were replicated on the 8+ data. Each step of the analyses and the outcomes are reported in full in the Supplementary 
materials (see Supplementary Tables 8-9). For clarity, only the final models and outcomes are reported here.

Outcomes from the parallel analyses and EFA identified that a three-factor solution consisting of phonological processing, processing speed and executive factors was the best fit to the 8+ data. A CFA was performed on the three-factor solution identified by the EFA (Figure 4). For diagrammatic purposes, the factors have been positioned in the same order as those for the whole sample. Fit indices revealed that this model was an acceptable fit to the data, $\chi^{2}(101)$ $=258.84, \mathrm{RMSEA}=0.053(90 \%$ confidence interval $[\mathrm{CI}]=0.045,0.060), \mathrm{CFI}=0.910, \mathrm{SRMR}$ $=0.053$. These factor scores were saved and entered into path models to explore links with learning.

\section{Insert Figure 4 here}

The three dimensions identified for the $8+$ data were consistent with those identified for the whole sample: both had factors corresponding to phonological processing, processing speed and executive function. This was despite additional measures being entered into the model for the 8+ group, and the sample including fewer children. Some measures included in the whole sample analysis shifted factors in the 8+ model (e.g. alliteration loaded on the speed factor in the whole sample analysis and the phonological factor in the analysis of the $8+$ data), and some had weak loadings so were not included in the final CFA model for the $8+$ group (e.g. SRT and Vigil).

To test whether the original model derived for the whole sample fit the smaller $8+$ sample when exactly the same measures were included (i.e. excluding the additional measures of executive function administered only to the $8+$ children), tests of measurement invariance were conducted comparing children aged 5-7 years to those aged 8+. These confirmed that the original three-factor structure identified for the whole sample was an acceptable fit for both groups (Supplementary Table 10). When factor loadings were constrained, metric invariance was violated, $\Delta \chi 2=40.96, \Delta \mathrm{df}=10, p<.001$. Inspection of factor loadings and modification indices showed the largest discrepancy occurred for Backward Digit Recall (children 5-7 years: 0.783, children 8+ years:0.675), and when this parameter was allowed to vary between groups, partial metric invariance was achieved such that equality constraining the other nine factor loadings did not adversely affect fit, $\Delta \chi 2=10.15, \Delta \mathrm{df}=9, p=.339$. 


\section{Links between cognition and learning for children aged eight and above}

Cognitive factor scores derived from the 8+ CFA were used in the following analyses. The cognitive and learning measures were all positively and significantly correlated (Supplementary Table 11 and Supplementary Figure 4). Mathematics and vocabulary were most strongly associated with the executive factor ( $r=.63$ and $r=.57$, respectively), and reading and spelling with the phonological factor ( $r=.60$ and $r=.50$, respectively). Multi-group path analyses established that phonological processing predicted reading and spelling, $p \mathrm{~s}<.001$. Mathematics was significantly predicted by executive function, $p<.001$, and both executive function $(p<.001)$ and phonological processing $(p=.011)$ predicted vocabulary (see Supplementary Table 12 and Figure 5).

Insert Figure 5 here

\section{Children aged eight and over, with and without $A D H D$}

Mirroring the analyses on the whole sample, the fit of the cognitive dimensions and their links with learning were compared between those with $(\mathrm{N}=192)$ and without ADHD $(\mathrm{N}=374)$. Descriptive statistics are provided in Table 5.

\section{Insert Table 5 here}

The groups performed similarly on the cognitive and learning measures, but those with ADHD had significantly higher scores on the Motor Speed, Cancellation, Number-Letter Switching, reading and spelling tasks than those without ADHD. The children in the ADHD group with a confirmed diagnosis scored significantly more poorly on the Mr X and Matrix Reasoning tasks, and all the learning measures, relative to those with a possible ADHD diagnosis (see Supplementary Table 13). Tests of measurement invariance revealed that the three factor cognitive model met metric invariance (see Supplementary Table 14 for details), indicating it was an acceptable fit for both groups, even when children with possible ADHD were removed from the analysis (see Supplementary Table 15). There were no differences in the pathways between cognition and learning for those with and without ADHD (see Table 6). For both groups, phonological processing was significantly associated with reading, spelling, and vocabulary, and executive function with maths and vocabulary. 
A three-factor latent model with factors of phonological processing, speed and executive function therefore provided the best fit to the $8+$ data, and was structurally and metrically invariant across those with and without ADHD. In all cases, phonological processing shared the strongest links with literacy outcomes, and executive function with maths.

\section{Discussion}

This study used a data-driven approach to identify the cognitive dimensions that mediate learning in a large heterogeneous sample of children with common learning-related difficulties. The children were identified as having functional problems in at least one of the areas of attention, learning or memory by a health or education professional. A substantial minority had been diagnosed with ADHD and other conditions. The following questions were addressed.

\section{What are the broad dimensions of cognitive skills in this population?}

Three dimensions of cognitive skill were identified using exploratory and confirmatory factor analysis. One relates to the broad set of phonological skills tapped by tasks involving verbal STM and phonological or verbal processing. A second dimension draws on tasks requiring the production of a speeded response across information processing activities ranging from rapid naming of printed words to visual search for a target digit in a display of mixed digits. This corresponds to a processing speed construct (see also, Kail \& Salthouse, 1994; Moll, Göbel, Gooch, Landerl, \& Snowling, 2016). The third dimension reflects the flexible, high-level control of cognitive processes and is linked with measures of nonverbal reasoning, planning, visuo-spatial STM, visuo-spatial WM, and verbal WM. The three dimensions were invariant across age groups and ADHD status and correlated highly with one another. Strong associations between cognitive test scores are ubiquitous in individual differences studies and have been suggested to reflect the 'positive manifold' of intelligence arising from mutually beneficial interactions between cognitive processes during development (Kievit et al., 2017; Van Der Maas et al., 2006).

These outcomes provide new information about how the cognitive skills of children with mixed learning-related problems are differentiated. The identification of dimensions of executive control, phonological processing and processing speed is consistent with a substantial body of evidence from cognitive developmental psychology. In contrast, the absence of a distinct WM construct deviates markedly from conventional developmental and neuropsychological taxonomies of cognition (Keith, Fine, Taub, Reynolds, \& Kranzler, 2006; 
Lezak, Howieson, Loring, \& Fischer, 2004). Measures of verbal and visuo-spatial WM and of visuo-spatial STM loaded highly on the executive control dimension, defined as such here because it also encompasses other executive abilities including spatial planning and nonverbal reasoning. The close association between visuo-spatial STM and domain-general WM itself is consistent with evidence from experimental, neuropsychological and individual differences studies demonstrating that these tasks have a common reliance on domain-general attentional resources (Alloway, Gathercole, \& Pickering, 2006; Kane et al., 2004; Morey \& Miron, 2016; Pearson, Ball, \& Smith, 2014; St Clair-Thompson \& Gathercole, 2006). Their linkage to a single factor also encompassing planning and nonverbal reasoning abilities adds weight to proposals that the executive component of the influential multi-component model of WM advanced by Baddeley, Hitch and colleagues (e.g., Baddeley, 2000) shares common attentional resources with the broader set of executive functions that differentiate both typically and atypically developing children (Castellanos, Sonuga-Barke, Milham, \& Tannock, 2006; Jarvis \& Gathercole, 2003).

\section{How are the cognitive dimensions linked with literacy, mathematics and vocabulary?}

As expected given the sample selection criteria, the sample has lower attainment levels in literacy and mathematics than the typical school population. However, their vocabulary knowledge, indexed by picture-word matching, was age-appropriate. The primary goal of the study was to discover how learning is linked with the principal dimensions of cognitive skill in these struggling learners. The results identify distinct cognitive pathways to different domains of learning. Reading was associated with both phonological processing skills and processing speed across the whole sample. However, reading was only related to processing speed in those with ADHD, with faster response speeds linked with higher reading scores. Spelling and vocabulary knowledge were linked with phonological processing in the whole sample, while mathematical abilities were uniquely linked to the executive dimension.

The severity of learning difficulties in literacy and mathematics was therefore principally linked to just two cognitive dimensions: phonological processing and executive control. Progress in the areas relating most directly to language - reading, spelling and vocabulary was associated with the strength of phonological processing skills. In contrast, mathematical abilities were linked with executive skills. These two aspects of learning difficulty co-occurred in many children, with $34 \%$ scoring more than 1SD below the population mean in both areas. These children are more likely to have more marked impairments in both phonological and 
executive skills, whereas cognitive deficits are more likely to be limited to a single dimension in individuals with more specific difficulties in either literacy or mathematics. Similar outcomes have been reported in studies using group designs applying strict inclusionary and exclusionary criteria to distinguish children with problems extending across literacy and mathematics from those with mathematical difficulties only ((Moll, Göbel, \& Snowling, 2015; Szucs et al., 2013). The present findings establish that these domain-specific links between cognitive skills and learning extend to a large mixed sample of children identified by practitioners as having learning-related difficulties.

\section{Are the same cognitive dimensions linked with learning in children with and without} ADHD?

Of the sample, 198 children had a diagnosis of ADHD and 57 were undergoing the final stages of assessment for the condition. Their inclusion provided the opportunity to distinguish between two potential explanations of why children with this common developmental disorder often experience difficulties in learning. According to the dual-deficit account (Castellanos et al., 2005; Solanto, Arnsten, \& Castellanos, 2001; E. Sonuga-Barke et al., 2010; E. J. S. SonugaBarke, 2002), children with ADHD and those with specific learning difficulties alone have a common impairment in the neurobiological pathway serving the cognitive systems that underpin standard neuropsychological assessments. The two populations are distinguished by an additional deficit in ADHD to a second pathway that supports the emotional regulation of cognition, and which gives rise to impulsive behaviour. A contrasting position is that learning difficulties in ADHD are a consequence of this restless and impulsive behaviour, either in part or in full. Whereas this latter position predicts that cognitive skills will have a weaker association with learning in children with $\mathrm{ADHD}$, the dual-deficit account predicts parity in the links between cognition and learning in children with and without ADHD.

The same cognitive model of phonological processing, processing speed and executive dimensions characterised both the children with and without ADHD in the sample. This remained true when the ADHD group included only those with a confirmed diagnosis of the condition. Links between these dimensions and learning were broadly comparable too, with strong associations between phonological skills and both literacy and vocabulary, and between executive skills and mathematics. However, a new discovery was that learning attainments in children with ADHD showed increased reliance on two of the cognitive dimensions: the association between maths attainments and executive skills was stronger, and there was a 
significant link between literacy and processing speed that was absent in children without ADHD.

These outcomes are inconsistent with both hypotheses. First, the finding that learning attainments were strongly determined by cognitive skills rules out the possibility that learning difficulties in children with ADHD are a simple consequence of impulsive and hyperactive behaviours in classroom settings. Second, the greater sensitivity of learning to these cognitive skills is inconsistent with a parsimonious view that learning problems have the same cognitive origins in children with and without ADHD (e.g., Sonuga-Barke, 2002, 2010). Some insight into the interplay of factors that constrain learning in ADHD is provided by the fact that strong executive skills were associated with higher mathematics scores in the children with than without ADHD. This suggests that in the case of attainment in mathematics at least, robust executive skills may compensate for the adverse impact of the behavioural problems of ADHD. A corresponding compensatory strategy may also underpin the stronger link between processing speed and literacy in this group. Processing speed is an area of relative strength for children with ADHD (Holmes et al., 2014), and many studies across different developmental populations have demonstrated close links between this skill and literacy (e.g., Moll et al., 2015). It may be that faster processing rates mitigate the negative impacts of impulsive and hyperactive behaviours for reading. More generally, these data suggest that capitalizing on areas of cognitive strengths may play an important role in overcoming the negative consequences of core ADHD symptoms on learning.

\section{Limitations and strengths}

In order to recruit the target mixed population of struggling learners, the sampling frame adopted in this study differed markedly from the standard approach of applying stringent inclusionary and exclusionary criteria to select and compare children with specific learning problems to typically-developing children. It was guided neither by diagnostic status nor by quantitative inclusion criteria. The sole criterion was that professionals in education or health services had observed the children to have learning-related issues. This allowed us to recruit a large and representative sample of children experiencing a wide range of common problems. The absence of strict exclusion criteria led to the inclusion of many children with additional neurodevelopmental and mental health problems.

While critical to addressing the study goals, this functionally-defined recruitment criterion brings potential limitations. In particular, it remains an open question whether the 
findings will generalize to samples adopting markedly different selection criteria. However, our own analyses investigating this potential challenge suggest our findings are reassuringly robust. The three-dimensional cognitive model fits the data from children across the wide range of school years and is an equally good fit for children with and without ADHD. Furthermore, the cognitive pathways to learning identified in this mixed population of children with functionally-defined problems - linking phonological processing and executive deficits to literacy and mathematical difficulties, respectively - conform closely to those of more conventionally-defined samples. Without this change of sampling strategy, we would not know that this is the case.

Finally, we acknowledge that while the present study adopted a dimensional, transdiagnostic approach to characterizing cognition and learning, there is great value in adopting multiple analytic approaches to deepen and extend understanding of developmental disorders. For example, machine learning methods have distinguished subgroups of the children in the cohort with distinct individual profiles of cognition, learning and behaviour (Astle, Bathelt, CALM Team, \& Holmes, 2019; Bathelt et al., 2018), and network analysis has identified inter-related behavioural and cognitive symptoms that are not captured by traditional diagnostic criteria (Mareva \& Holmes, 2019). Using structural equation modelling, work has examined a priori distinctions between fluid and crystallized abilities (Simpson-Kent et al., 2020) and evaluated conceptually distinct models of hierarchical, cognitive-only factors (Fuhrmann, Simpson-Kent, Bathelt, \& Kievit, 2019). These findings have yet to be integrated in a single, multi-level model of learning difficulties. However, they clearly demonstrate the value of applying complementary analytic lenses to rich datasets such as the CALM cohort in making real progress towards a systems neuroscience understanding of cognitive development and its disorders. The approach also generates new insights into how to tailor support for the many children failing to thrive in school (Casey et al., 2014; Mittal \& Wakschlag, 2017; E. J. S. Sonuga-Barke et al., 2016).

\section{Ethics Approval and Consent to Participate}

Ethical approval was granted by the National Health Service (REC: 13/EE/0157). Parents/caregivers provided written consent and child verbal assent was obtained.

\section{Availability of data and material}


The dataset generated and analysed has not been made publicly available yet as the study is still ongoing. The data will be made publically available via managed open access once the study is complete. Analysis scripts are available from the corresponding author upon request.

\section{Competing interests}

The authors declare that they have no competing interests.

\section{Author contributions:}

SG and JH conceived of the study, interpreted the results and wrote the manuscript. JG completed the data analysis, contributed to data collection and writing, and wrote the results and supplementary materials. RK contributed to writing and advised on statistical analysis. $\mathrm{AB}$ contributed to early drafts of sections of the manuscript and contributed to data collection. All authors read and agreed to the final version of the submission.

\section{Acknowledgements:}

The Centre for Attention Learning and Memory (CALM) research clinic is based at and supported by funding from the MRC Cognition and Brain Sciences Unit University of Cambridge. The lead investigators are Duncan Astle, Kate Baker, Susan Gathercole, Joni Holmes, Rogier Kievit and Tom Manly. Data collection is assisted by a team of researchers and $\mathrm{PhD}$ students that includes Joe Bathelt, Giacomo Bignardi, Sarah Bishop, Erica Bottacin, Lara Bridge, Diandra Bkric, Annie Bryant, Sally Butterfield, Elizabeth Byrne, Gemma Crickmore, Edwin Dalmaijer; Fánchea Daly, Tina Emery, Grace Franckel, Laura Forde, Delia Fuhrmann, Andrew Gadie, Sara Gharooni, Jacalyn Guy, Erin Hawkins, Agniezska Jaroslawska, Sara Joeghan, Amy Johnson, Jonathon Jones, Elise Ng-Cordell, Sinéad O’Brien, Cliodhna O’Leary, Joseph Rennie, Ivan Simpson-Kent, Roma Siugzdaite, Tess Smith, Stepheni Uh, Francesca Woolgar, and Mengya Zhang. The authors wish to thank the many professionals working in children's services in the South-East and East of England for their support, and to the children and their families for giving up their time to visit the clinic. 


\section{References}

Allen, R. J., Hitch, G. J., Mate, J., \& Baddeley, A. D. (2012). Feature binding and attention in working memory: A resolution of previous contradictory findings. The Quarterly Journal of Experimental Psychology, 65(12), 2369-2383.

Alloway, T. (2007). Automated Working Memory Assessment (AWMA) London. UK: Pearson Assessment.

Alloway, T. P., Gathercole, S. E., \& Pickering, S. J. (2006). Verbal and visuospatial shortterm and working memory in children: Are they separable? Child Development, 77(6), $1698-1716$.

American Psychiatric Association. (2013). Diagnostic and statistical manual of mental disorders. Diagnostic and Statistical Manual of Mental Disorders, 5.

Astle, D. E., Bathelt, J., Team, C., \& Holmes, J. (2019). Remapping the cognitive and neural profiles of children who struggle at school. Developmental Science, 22(1), e12747.

Baddeley, A. (2000). The episodic buffer: a new component of working memory? Trends in Cognitive Sciences, 4(11), 417-423.

Baddeley, A. (2010). Working memory. Current Biology, 20(4), R136-R140.

BALFANZ, R., HERZOG, L., \& MAC IVER, D. J. (2007). Preventing Student Disengagement and Keeping Students on the Graduation Path in Urban Middle-Grades Schools: Early Identification and Effective Interventions. Educational Psychologist, 42(4), 223-235. https://doi.org/10.1080/00461520701621079

Barbaresi, W. J., Katusic, S. K., Colligan, R. C., Weaver, A. L., \& Jacobsen, S. J. (2005). Math learning disorder: Incidence in a population-based birth cohort, 1976-82, Rochester, Minn. Ambulatory Pediatrics, 5(5), 281-289.

Barbot, B., Krivulskaya, S., Hein, S., Reich, J., Thuma, P. E., \& Grigorenko, E. L. (2016). Identifying learning patterns of children at risk for Specific Reading Disability. Developmental Science, 19(3), 402-418. https://doi.org/10.1111/desc.12313

Bathelt, J., Holmes, J., Astle, D. E., Gathercole, S., Astle, D., Manly, T., \& Kievit, R. (2018). Data-Driven Subtyping of Executive Function-Related Behavioral Problems in 
Children. Journal of the American Academy of Child \& Adolescent Psychiatry, 57(4), $252-262$.

Bishop, A. G., \& League, M. B. (2006). Identifying a multivariate screening model to predict reading difficulties at the onset of kindergarten: A longitudinal analysis. Learning Disability Quarterly, 29(4), 235-252.

Bishop, D. V. M., \& Snowling, M. J. (2004). Developmental dyslexia and specific language impairment: Same or different? Psychological Bulletin, 130(6), 858.

Blair, C., Gamson, D., Thorne, S., \& Baker, D. (2005). Rising mean IQ: Cognitive demand of mathematics education for young children, population exposure to formal schooling, and the neurobiology of the prefrontal cortex. Intelligence, 33(1), 93-106. https://doi.org/https://doi.org/10.1016/j.intell.2004.07.008

Bonifacci, P., \& Snowling, M. J. (2008). Speed of processing and reading disability: A crosslinguistic investigation of dyslexia and borderline intellectual functioning. Cognition, 107(3), 999-1017.

Booth, J. N., Boyle, J. M. E., \& Kelly, S. W. (2010). Do tasks make a difference? Accounting for heterogeneity of performance of children with reading difficulties on tasks of executive function: Findings from a meta-analysis. British Journal of Developmental Psychology, 28(1), 133-176.

Bowyer-Crane, C., Snowling, M. J., Duff, F. J., Fieldsend, E., Carroll, J. M., Miles, J., ... Hulme, C. (2008). Improving early language and literacy skills: Differential effects of an oral language versus a phonology with reading intervention. Journal of Child Psychology and Psychiatry, 49(4), 422-432.

Bull, R., \& Johnston, R. S. (1997). Children's arithmetical difficulties: Contributions from processing speed, item identification, and short-term memory. Journal of Experimental Child Psychology, 65(1), 1-24.

Bull, R., \& Lee, K. (2014). Executive Functioning and Mathematics Achievement. Child Development Perspectives, 8(1), 36-41. https://doi.org/10.1111/cdep.12059

Bull, R., \& Scerif, G. (2001). Executive Functioning as a Predictor of Children's Mathematics Ability: Inhibition, Switching, and Working Memory. Developmental 
Neuropsychology, 19(3), 273-293. https://doi.org/10.1207/S15326942DN1903_3

Bynner, J., Foudouli, V., \& Parsons, S. (2005). Measuring basic skills for longitudinal study: the design and development of instruments for use with cohort members in the age 34 follow-up in the 1970 British Cohort Study (BCS70).

Cain, K., Oakhill, J., \& Lemmon, K. (2004). Individual differences in the inference of word meanings from context: The influence of reading comprehension, vocabulary knowledge, and memory capacity. Journal of Educational Psychology, 96(4), 671.

Cantor, J., \& Engle, R. W. (1993). Working-memory capacity as long-term memory activation: An individual-differences approach. Journal of Experimental Psychology: Learning, Memory, and Cognition, 19(5), 1101.

Carretti, B., Borella, E., Cornoldi, C., \& De Beni, R. (2009). Role of working memory in explaining the performance of individuals with specific reading comprehension difficulties: A meta-analysis. Learning and Individual Differences, 19(2), 246-251.

Cartwright, K. B. (2012). Insights from cognitive neuroscience: The importance of executive function for early reading development and education. Early Education \& Development, 23(1), 24-36.

Casey, B. J., Oliveri, M. E., \& Insel, T. (2014). A neurodevelopmental perspective on the research domain criteria (RDoC) framework. Biological Psychiatry, 76(5), 350-353.

Castellanos, F. X., Lee, P. P., Sharp, W., Jeffries, N. O., Greenstein, D. K., Clasen, L. S., ... Rapoport, J. L. (2002). Developmental Trajectories of Brain Volume Abnormalities in Children and Adolescents With Attention-Deficit/Hyperactivity Disorder. JAMA, 288(14), 1740-1748. https://doi.org/10.1001/jama.288.14.1740

Castellanos, F. X., Sonuga-Barke, E. J. S., Milham, M. P., \& Tannock, R. (2006).

Characterizing cognition in ADHD: beyond executive dysfunction. Trends in Cognitive Sciences, 10(3), 117-123.

Castellanos, F. X., Sonuga-Barke, E. J. S., Scheres, A., Di Martino, A., Hyde, C., \& Walters, J. R. (2005). Varieties of Attention-Deficit/Hyperactivity Disorder-Related IntraIndividual Variability. Biological Psychiatry, 57(11), 1416-1423. https://doi.org/https://doi.org/10.1016/j.biopsych.2004.12.005 
Castles, A., \& Friedmann, N. (2014). Developmental dyslexia and the phonological deficit hypothesis. Mind \& Language, 29(3), 270-285.

Catts, H. W., Compton, D., Tomblin, J. B., \& Bridges, M. S. (2012). Prevalence and nature of late-emerging poor readers. Journal of Educational Psychology, 104(1), 166.

Catts, H. W., Fey, M. E., Zhang, X., \& Tomblin, J. B. (2001). Estimating the risk of future reading difficulties in kindergarten children. Language, Speech, and Hearing Services in Schools.

Catts, H. W., Gillispie, M., Leonard, L. B., Kail, R. V, \& Miller, C. A. (2002). The role of speed of processing, rapid naming, and phonological awareness in reading achievement. Journal of Learning Disabilities, 35(6), 510-525.

Child, A. E., Cirino, P. T., Fletcher, J. M., Willcutt, E. G., \& Fuchs, L. S. (2019). A cognitive dimensional approach to understanding shared and unique contributions to reading, math, and attention skills. Journal of Learning Disabilities, 52(1), 15-30.

Cirino, P. T., Child, A. E., \& Macdonald, K. T. (2018). Longitudinal predictors of the overlap between reading and math skills. Contemporary Educational Psychology, 54, 99-111. https://doi.org/https://doi.org/10.1016/j.cedpsych.2018.06.002

Clayton, F. J., West, G., Sears, C., Hulme, C., \& Lervåg, A. (2019). A Longitudinal Study of Early Reading Development: Letter-Sound Knowledge, Phoneme Awareness and RAN, but Not Letter-Sound Integration, Predict Variations in Reading Development. Scientific Studies of Reading, 1-17.

Coghill, D., \& Sonuga-Barke, E. J. S. (2012). Annual Research Review: Categories versus dimensions in the classification and conceptualisation of child and adolescent mental disorders - implications of recent empirical study. Journal of Child Psychology and Psychiatry, 53(5), 469-489. https://doi.org/10.1111/j.1469-7610.2011.02511.x

Cohen, L., Dehaene, S., Vinckier, F., Jobert, A., \& Montavont, A. (2008). Reading normal and degraded words: Contribution of the dorsal and ventral visual pathways. Neuroimage, 40(1), 353-366.

Cohen, M. (1997). Children's memory scale. Psychological Corporation.

Cortese, S., Ferrin, M., Brandeis, D., Buitelaar, J., Daley, D., Dittmann, R. W., ... Stringaris, 
A. (2015). Cognitive training for attention-deficit/hyperactivity disorder: meta-analysis of clinical and neuropsychological outcomes from randomized controlled trials. Journal of the American Academy of Child \& Adolescent Psychiatry, 54(3), 164-174.

Cuthbert, B. N., \& Insel, T. R. (2013). Toward the future of psychiatric diagnosis: the seven pillars of RDoC. BMC Medicine, 11(1), 126.

De Beer, J., Engels, J., Heerkens, Y., \& van der Klink, J. (2014). Factors influencing work participation of adults with developmental dyslexia: a systematic review. BMC Public Health, 14(1), 77.

De Beni, R., \& Palladino, P. (2000). Intrusion errors in working memory tasks: Are they related to reading comprehension ability? Learning and Individual Differences, 12(2), $131-143$.

de Jong, P. F., Bitter, D. J. L., van Setten, M., \& Marinus, E. (2009). Does phonological recoding occur during silent reading, and is it necessary for orthographic learning? Journal of Experimental Child Psychology, 104(3), 267-282. https://doi.org/https://doi.org/10.1016/j.jecp.2009.06.002

De Smedt, B., Swillen, A., Verschaffel, L., \& Ghesquière, P. (2009). Mathematical learning disabilities in children with 22q11.2 deletion syndrome: A review. Developmental Disabilities Research Reviews, 15(1), 4-10. https://doi.org/10.1002/ddrr.44

Dehaene, S., Cohen, L., Sigman, M., \& Vinckier, F. (2005). The neural code for written words: a proposal. Trends in Cognitive Sciences, 9(7), 335-341.

Delis, D. C., Kaplan, E., Kramer, J. H., Delis, D., \& Kramer, J. (2001). Delis-Kaplan executive function system ( $D$-KEFS). Examiner's manual.

Dirks, E., Spyer, G., van Lieshout, E. C. D. M., \& de Sonneville, L. (2008). Prevalence of combined reading and arithmetic disabilities. Journal of Learning Disabilities, 41(5), 460-473.

Duinmeijer, I., de Jong, J., \& Scheper, A. (2012). Narrative abilities, memory and attention in children with a specific language impairment. International Journal of Language \& Communication Disorders, 47(5), 542-555. https://doi.org/10.1111/j.14606984.2012.00164.x 
Duncan, J. (2013). The structure of cognition: attentional episodes in mind and brain. Neuron, 80(1), 35-50.

Dunn, L. M., \& Dunn, D. M. (2007). PPVT-4: Peabody picture vocabulary test. Pearson Assessments.

Emerson, E., \& Hatton, C. (2007). Mental health of children and adolescents with intellectual disabilities in Britain. The British Journal of Psychiatry, 191(6), 493-499.

Follmer, D. J. (2018). Executive function and reading comprehension: A meta-analytic review. Educational Psychologist, 53(1), 42-60.

Frederickson, N., Frith, U., \& Reason, R. (1997). Phonological Assessment Battery (PhAB).: Manual and Test Materials. NFERNelson.

Friso-van den Bos, I., van der Ven, S. H. G., Kroesbergen, E. H., \& van Luit, J. E. H. (2013). Working memory and mathematics in primary school children: A meta-analysis. Educational Research Review, 10, 29-44. https://doi.org/https://doi.org/10.1016/j.edurev.2013.05.003

Fuchs, L. S., Compton, D. L., Fuchs, D., Paulsen, K., Bryant, J. D., \& Hamlett, C. L. (2005). The Prevention, Identification, and Cognitive Determinants of Math Difficulty. Journal of Educational Psychology, 97(3), 493-513. https://doi.org/10.1037/0022-0663.97.3.493

Fuhrmann, D., Simpson-Kent, I. L., Bathelt, J., \& Kievit, R. A. (2019). A hierarchical watershed model of fluid intelligence in childhood and adolescence. BioRxiv, 435719.

Gathercole, S. E., \& Alloway, T. packiam. (2008). Working memory and learning : a practical guide for teachers. SAGE Publications.

Gathercole, S. E., \& Baddeley, A. D. (1996). The children's test of nonword repetition. Pearson.

Gathercole, S. E., Brown, L., \& Pickering, S. J. (2003). Working memory assessments at school entry as longitudinal predictors of National Curriculum attainment levels. Educational and Child Psychology, 20(3), 109-122.

Gathercole, S. E., Durling, E., Evans, M., Jeffcock, S., \& Stone, S. (2008). Working memory abilities and children's performance in laboratory analogues of classroom activities. 
Applied Cognitive Psychology: The Official Journal of the Society for Applied Research in Memory and Cognition, 22(8), 1019-1037.

Geary, D. C. (1993). Mathematical disabilities: Cognitive, neuropsychological, and genetic components. Psychological Bulletin, 114(2), 345.

Geary, D. C. (2003). Learning disabilities in arithmetic: Problem-solving differences and cognitive deficits. In Handbook of learning disabilities. (pp. 199-212). New York, NY, US: The Guilford Press.

Geary, D. C. (2011). Consequences, characteristics, and causes of mathematical learning disabilities and persistent low achievement in mathematics. Journal of Developmental and Behavioral Pediatrics : JDBP, 32(3), 250-263. https://doi.org/10.1097/DBP.0b013e318209edef

Geary, D. C. (2013). Early foundations for mathematics learning and their relations to learning disabilities. Current Directions in Psychological Science, 22(1), 23-27.

Geary, D. C., Bow-Thomas, C. C., \& Yao, Y. (1992). Counting knowledge and skill in cognitive addition: A comparison of normal and mathematically disabled children. Journal of Experimental Child Psychology, 54(3), 372-391. https://doi.org/https://doi.org/10.1016/0022-0965(92)90026-3

Geary, D. C., Brown, S. C., \& Samaranayake, V. A. (1991). Cognitive addition: A short longitudinal study of strategy choice and speed-of-processing differences in normal and mathematically disabled children. Developmental Psychology, Vol. 27, pp. 787-797. https://doi.org/10.1037/0012-1649.27.5.787

Gersten, R., Jordan, N. C., \& Flojo, J. R. (2005). Early identification and interventions for students with mathematics difficulties. Journal of Learning Disabilities, 38(4), 293-304.

Geurts, H. M., van der Oord, S., \& Crone, E. A. (2006). Hot and Cool Aspects of Cognitive Control in Children with ADHD: Decision-Making and Inhibition. Journal of Abnormal Child Psychology, 34(6), 811-822. https://doi.org/10.1007/s10802-006-9059-2

Gooch, D., Snowling, M. J., \& Hulme, C. (2012). Reaction time variability in children with ADHD symptoms and/or dyslexia. Developmental Neuropsychology, 37(5), 453-472.

Hamann, M. S., \& Ashcraft, M. H. (1985). Simple and complex mental addition across 
development. Journal of Experimental Child Psychology, 40(1), 49-72.

Hecht, S. A., Torgesen, J. K., Wagner, R. K., \& Rashotte, C. A. (2001). The Relations between Phonological Processing Abilities and Emerging Individual Differences in Mathematical Computation Skills: A Longitudinal Study from Second to Fifth Grades. Journal of Experimental Child Psychology, 79(2), 192-227. https://doi.org/https://doi.org/10.1006/jecp.2000.2586

Herrmann, J. A., Matyas, T., \& Pratt, C. (2006). Meta-analysis of the nonword reading deficit in specific reading disorder. Dyslexia, 12(3), 195-221.

Hitch, G. J., \& McAuley, E. (1991). Working memory in children with specific arithmetical learning difficulties. British Journal of Psychology, 82(3), 375-386. https://doi.org/10.1111/j.2044-8295.1991.tb02406.x

Hobson, R. P. (2014). The coherence of autism. Autism, 18(1), 6-16.

Holloway, I. D., \& Ansari, D. (2008). Domain-specific and domain-general changes in children's development of number comparison. Developmental Science, 11(5), 644-649. https://doi.org/10.1111/j.1467-7687.2008.00712.x

Holmes, J., Adams, J. W., \& Hamilton, C. J. (2008). The relationship between visuospatial sketchpad capacity and children's mathematical skills. European Journal of Cognitive Psychology, 20(2), 272-289. https://doi.org/10.1080/09541440701612702

Holmes, J., Bryant, A., Gathercole, S. E., \& Team, the C. (2019). Protocol for a transdiagnostic study of children with problems of attention, learning and memory (CALM). BMC Pediatrics, 19(1), 10. https://doi.org/10.1186/s12887-018-1385-3

Holmes, J., Hilton, K. A., Place, M., Alloway, T. P., Elliott, J. G., \& Gathercole, S. E. (2014). Children with low working memory and children with ADHD: same or different? . Frontiers in Human Neuroscience , Vol. 8, p. 976. Retrieved from https://www.frontiersin.org/article/10.3389/fnhum.2014.00976

Huettig, F., Lachmann, T., Reis, A., \& Petersson, K. M. (2018). Distinguishing cause from effect-many deficits associated with developmental dyslexia may be a consequence of reduced and suboptimal reading experience. Language, Cognition and Neuroscience, 33(3), 333-350. 
Irwin, L. N., Kofler, M. J., Soto, E. F., \& Groves, N. B. (2019). Do children with attentiondeficit/hyperactivity disorder (ADHD) have set shifting deficits? Neuropsychology, Vol. 33, pp. 470-481. https://doi.org/10.1037/neu0000546

Jaroslawska, A. J., Gathercole, S. E., Logie, M. R., \& Holmes, J. (2016). Following instructions in a virtual school: Does working memory play a role? Memory \& Cognition, 44(4), 580-589.

Jarvis, H. L., \& Gathercole, S. E. (2003). Verbal and non-verbal working memory and achievements on national curriculum tests at 11 and 14 years of age. Educational and Child Psychology, 20(3), 123-140.

Johnson, C., \& Goswami, U. (2010). Phonological awareness, vocabulary, and reading in deaf children with cochlear implants. Journal of Speech, Language, and Hearing Research.

Jordan, N. C., Hanich, L. B., \& Kaplan, D. (2003). A Longitudinal Study of Mathematical Competencies in Children With Specific Mathematics Difficulties Versus Children With Comorbid Mathematics and Reading Difficulties. Child Development, 74(3), 834-850. https://doi.org/10.1111/1467-8624.00571

Jorgensen, T. D., Pornprasertmanit, S., Schoemann, A. M., \& Rosseel, Y. (2018). semTools: Useful tools for structural equation modeling. R package version 0.5-1.

Kail, R., \& Hall, L. K. (1994). Processing speed, naming speed, and reading. Developmental Psychology, 30(6), 949.

Kail, R., \& Salthouse, T. A. (1994). Processing speed as a mental capacity. Acta Psychologica, 86(2-3), 199-225.

Kane, M. J., Hambrick, D. Z., Tuholski, S. W., Wilhelm, O., Payne, T. W., \& Engle, R. W. (2004). The generality of working memory capacity: a latent-variable approach to verbal and visuospatial memory span and reasoning. Journal of Experimental Psychology: General, 133(2), 189.

Karalunas, S. L., Fair, D., Musser, E. D., Aykes, K., Iyer, S. P., \& Nigg, J. T. (2014). Subtyping Attention-Deficit/Hyperactivity Disorder Using Temperament Dimensions: Toward Biologically Based Nosologic Criteria. JAMA Psychiatry, 71(9), 1015-1024. 
https://doi.org/10.1001/jamapsychiatry.2014.763

Kassai, R., Futo, J., Demetrovics, Z., \& Takacs, Z. K. (2019). A meta-analysis of the experimental evidence on the near-and far-transfer effects among children's executive function skills. Psychological Bulletin, 145(2), 165.

Kaye, D. B. (1986). The development of mathematical cognition. Cognitive Development, $1(2), 157-170$

Keith, T. Z., Fine, J. G., Taub, G. E., Reynolds, M. R., \& Kranzler, J. H. (2006). Higher order, multisample, confirmatory factor analysis of the Wechsler Intelligence Scale for Children-Fourth Edition: What does it measure. School Psychology Review, 35(1), $108-127$.

Kieffer, M. J., Vukovic, R. K., \& Berry, D. (2013). Roles of attention shifting and inhibitory control in fourth-grade reading comprehension. Reading Research Quarterly, 48(4), $333-348$.

Kievit, R. A., Hofman, A. D., \& Nation, K. (2019). Mutualistic coupling between vocabulary and reasoning in young children: A replication and extension of the study by Kievit et al.(2017). Psychological Science, 30(8), 1245-1252.

Kievit, R. A., Lindenberger, U., Goodyer, I. M., Jones, P. B., Fonagy, P., Bullmore, E. T., ... Dolan, R. J. (2017). Mutualistic coupling between vocabulary and reasoning supports cognitive development during late adolescence and early adulthood. Psychological Science, 28(10), 1419-1431.

Kofler, M. J., Spiegel, J. A., Soto, E. F., Irwin, L. N., Wells, E. L., \& Austin, K. E. (2019). Do Working Memory Deficits Underlie Reading Problems in AttentionDeficit/Hyperactivity Disorder (ADHD)? Journal of Abnormal Child Psychology, 47(3), 433-446. https://doi.org/10.1007/s10802-018-0447-1

Kotov, R., Krueger, R. F., Watson, D., Achenbach, T. M., Althoff, R. R., Bagby, R. M., ... Zimmerman, M. (2017). The Hierarchical Taxonomy of Psychopathology (HiTOP): A dimensional alternative to traditional nosologies. Journal of Abnormal Psychology, Vol. 126, pp. 454-477. https://doi.org/10.1037/abn0000258

Krajewski, K., \& Schneider, W. (2009). Exploring the impact of phonological awareness, 
visual-spatial working memory, and preschool quantity-number competencies on mathematics achievement in elementary school: Findings from a 3-year longitudinal study. Journal of Experimental Child Psychology, 103(4), 516-531. https://doi.org/https://doi.org/10.1016/j.jecp.2009.03.009

Kudo, M. F., Lussier, C. M., \& Swanson, H. L. (2015). Reading disabilities in children: A selective meta-analysis of the cognitive literature. Research in Developmental Disabilities, 40, 51-62.

Laasonen, M., Smolander, S., Lahti-Nuuttila, P., Leminen, M., Lajunen, H.-R., Heinonen, K., ... Arkkila, E. (2018). Understanding developmental language disorder - the Helsinki longitudinal SLI study (HelSLI): a study protocol. BMC Psychology, 6(1), 24. https://doi.org/10.1186/s40359-018-0222-7

Landerl, K., \& Kölle, C. (2009). Typical and atypical development of basic numerical skills in elementary school. Journal of Experimental Child Psychology, 103(4), 546-565. https://doi.org/https://doi.org/10.1016/j.jecp.2008.12.006

Landerl, K., \& Moll, K. (2010). Comorbidity of learning disorders: prevalence and familial transmission. Journal of Child Psychology and Psychiatry, 51(3), 287-294.

Lervåg, A., \& Aukrust, V. G. (2010). Vocabulary knowledge is a critical determinant of the difference in reading comprehension growth between first and second language learners. Journal of Child Psychology and Psychiatry, 51(5), 612-620.

Lezak, M. D., Howieson, D. B., Loring, D. W., \& Fischer, J. S. (2004). Neuropsychological assessment. Oxford University Press, USA.

Li, Y., \& Geary, D. C. (2013). Developmental gains in visuospatial memory predict gains in mathematics achievement. PloS One, 8(7), e70160-e70160. https://doi.org/10.1371/journal.pone.0070160

Loe, I. M., \& Feldman, H. M. (2007). Academic and Educational Outcomes of Children With ADHD. Journal of Pediatric Psychology, 32(6), 643-654. https://doi.org/10.1093/jpepsy/js1054

Manly, T., Anderson, V., Crawford, J., George, M., Underbjerg, M., \& Robertson, I. (2016). Test of everyday attention for children. (TEA-Ch2) London. UK: Harcourt Assessment. 
Mareva, S., \& Holmes, J. (2019). Transdiagnostic associations across communication, cognitive, and behavioural problems in a developmentally at-risk population: a network approach. BMC Pediatrics, 19(1), 452.

Marzocchi, G. M., Oosterlaan, J., Zuddas, A., Cavolina, P., Geurts, H., Redigolo, D., ... Sergeant, J. A. (2008). Contrasting deficits on executive functions between ADHD and reading disabled children. Journal of Child Psychology and Psychiatry, 49(5), 543-552. https://doi.org/10.1111/j.1469-7610.2007.01859.x

Masten, A. S., \& Cicchetti, D. (2010). Developmental cascades. Development and Psychopathology, 22(3), 491-495.

McGrath, L. M., Pennington, B. F., Shanahan, M. A., Santerre-Lemmon, L. E., Barnard, H. D., Willcutt, E. G., ... Olson, R. K. (2011). A multiple deficit model of reading disability and attention-deficit/hyperactivity disorder: Searching for shared cognitive deficits. Journal of Child Psychology and Psychiatry, 52(5), 547-557.

McLean, J. F., \& Hitch, G. J. (1999). Working Memory Impairments in Children with Specific Arithmetic Learning Difficulties. Journal of Experimental Child Psychology, 74(3), 240-260. https://doi.org/https://doi.org/10.1006/jecp.1999.2516

Melby-Lervåg, M., \& Hulme, C. (2010). Serial and Free Recall in Children Can Be Improved by Training: Evidence for the Importance of Phonological and Semantic Representations in Immediate Memory Tasks. Psychological Science, 21(11), 1694-1700. https://doi.org/10.1177/0956797610385355

Melby-Lervåg, M., Lervåg, A., Lyster, S.-A. H., Klem, M., Hagtvet, B., \& Hulme, C. (2012). Nonword-repetition ability does not appear to be a causal influence on children's vocabulary development. Psychological Science, 23(10), 1092-1098.

Melby-Lervåg, M., Lyster, S. A. H., \& Hulme, C. (2012). Phonological skills and their role in learning to read: A meta-analytic review. Psychological Bulletin, 138(2), 322-352. https://doi.org/10.1037/a0026744

Metsala, J. L., Stanovich, K. E., \& Brown, G. D. A. (1998). Regularity effects and the phonological deficit model of reading disabilities: A meta-analytic review. Journal of Educational Psychology, 90(2), 279. 
Meyer, M. L., Salimpoor, V. N., Wu, S. S., Geary, D. C., \& Menon, V. (2010). Differential contribution of specific working memory components to mathematics achievement in 2nd and 3rd graders. Learning and Individual Differences, 20(2), 101-109. https://doi.org/https://doi.org/10.1016/j.lindif.2009.08.004

Mittal, V. A., \& Wakschlag, L. S. (2017). Research domain criteria (RDoC) grows up: Strengthening neurodevelopmental investigation within the RDoC framework. Journal of Affective Disorders, 216, 30.

Moll, K., Göbel, S. M., Gooch, D., Landerl, K., \& Snowling, M. J. (2016). Cognitive risk factors for specific learning disorder: Processing speed, temporal processing, and working memory. Journal of Learning Disabilities, 49(3), 272-281.

Moll, K., Göbel, S. M., \& Snowling, M. J. (2015). Basic number processing in children with specific learning disorders: Comorbidity of reading and mathematics disorders. Child Neuropsychology, 21(3), 399-417.

Moll, K., Kunze, S., Neuhoff, N., Bruder, J., \& Schulte-Körne, G. (2014). Specific learning disorder: prevalence and gender differences. PLoS One, 9(7).

Morais, J. (1987). Phonetic awareness and reading acquisition. Psychological Research, 49(2-3), 147-152.

Morais, J., \& Kolinsky, R. (2005). Literacy and Cognitive Change. In Blackwell Handbooks of Developmental Psychology. The science of reading: A handbook. (pp. 188-203). https://doi.org/10.1002/9780470757642.ch11

Morey, C. C., \& Miron, M. D. (2016). Spatial sequences, but not verbal sequences, are vulnerable to general interference during retention in working memory. Journal of Experimental Psychology: Learning, Memory, and Cognition, 42(12), 1907.

Mussolin, C., \& Noel, M.-P. (2008). Specific Retrieval Deficit from Long-Term Memory in Children with Poor Arithmetic Facts Abilities. The Open Psychology Journal, 1(1), 2634. https://doi.org/10.2174/1874350100801010026

Nation, K. (1999). Reading skills in hyperlexia: a developmental perspective. Psychological Bulletin, 125(3), 338.

Nation, K., Clarke, P., \& Snowling, M. J. (2002). General cognitive ability in children with 
reading comprehension difficulties. British Journal of Educational Psychology, 72(4), 549-560. https://doi.org/10.1348/00070990260377604

Nigg, J. T., Willcutt, E. G., Doyle, A. E., \& Sonuga-Barke, E. J. S. (2005). Causal Heterogeneity in Attention-Deficit/Hyperactivity Disorder: Do We Need Neuropsychologically Impaired Subtypes? Biological Psychiatry, 57(11), 1224-1230. https://doi.org/https://doi.org/10.1016/j.biopsych.2004.08.025

Owen, M. J. (2014). New Approaches to Psychiatric Diagnostic Classification. Neuron, 84(3), 564-571. https://doi.org/https://doi.org/10.1016/j.neuron.2014.10.028

Passolunghi, M. C., Mammarella, I. C., \& Altoè, G. (2008). Cognitive Abilities as Precursors of the Early Acquisition of Mathematical Skills During First Through Second Grades. Developmental Neuropsychology, 33(3), 229-250. https://doi.org/10.1080/87565640801982320

Pastor, P. N., \& Reuben, C. A. (2008). Diagnosed Attention Deficit Hyperactivity Disorder and Learning Disability: United States, 2004-2006. Data from the National Health Interview Survey. Vital and Health Statistics. Series 10, Number 237. ERIC.

Patel, T. K., Snowling, M. J., \& de Jong, P. F. (2004). A cross-linguistic comparison of children learning to read in English and Dutch. Journal of Educational Psychology, 96(4), 785.

Patros, C. H. G., Tarle, S. J., Alderson, R. M., Lea, S. E., \& Arrington, E. F. (2019). Planning deficits in children with attention-deficit/hyperactivity disorder (ADHD): A metaanalytic review of tower task performance. Neuropsychology, Vol. 33, pp. 425-444. https://doi.org/10.1037/neu0000531

Pearson, D. G., Ball, K., \& Smith, D. T. (2014). Oculomotor preparation as a rehearsal mechanism in spatial working memory. Cognition, 132(3), 416-428.

Peng, P., \& Fuchs, D. (2016). A meta-analysis of working memory deficits in children with learning difficulties: Is there a difference between verbal domain and numerical domain? Journal of Learning Disabilities, 49(1), 3-20.

Peng, P., \& Kievit, R. A. (2019). The Development of Academic Achievement and Cognitive Abilities: A Bidirectional Perspective. Child Development Perspectives. 
Peng, P., Namkung, J., Barnes, M., \& Sun, C. (2016). A meta-analysis of mathematics and working memory: Moderating effects of working memory domain, type of mathematics skill, and sample characteristics. Journal of Educational Psychology, 108(4), 455-473. https://doi.org/10.1037/edu0000079

Peng, P., Wang, C., \& Namkung, J. (2018). Understanding the Cognition Related to Mathematics Difficulties: A Meta-Analysis on the Cognitive Deficit Profiles and the Bottleneck Theory. Review of Educational Research, 88(3), 434-476. https://doi.org/10.3102/0034654317753350

Perfetti, C. (2007). Reading ability: Lexical quality to comprehension. Scientific Studies of Reading, 11(4), 357-383.

Peterson, R. L., \& Pennington, B. F. (2012). Developmental dyslexia. The Lancet, 379(9830), 1997-2007.

Preßler, A.-L., Könen, T., Hasselhorn, M., \& Krajewski, K. (2014). Cognitive preconditions of early reading and spelling: a latent-variable approach with longitudinal data. Reading and Writing, 27(2), 383-406.

Putnick, D. L., \& Bornstein, M. H. (2016). Measurement invariance conventions and reporting: The state of the art and future directions for psychological research. Developmental Review, 41, 71-90.

R.-Mercier, A., Masson, M., Bussières, E.-L., \& Cellard, C. (2018). Common transdiagnostic cognitive deficits among people with psychiatric disorders exposed to childhood maltreatment: a meta-analysis. Cognitive Neuropsychiatry, 23(3), 180-197. https://doi.org/10.1080/13546805.2018.1461617

Reininghaus, U., Böhnke, J. R., Chavez-Baldini, U., Gibbons, R., Ivleva, E., Clementz, B. A., ... Tamminga, C. A. (2019). Transdiagnostic dimensions of psychosis in the BipolarSchizophrenia Network on Intermediate Phenotypes (B-SNIP). World Psychiatry, 18(1), 67-76. https://doi.org/10.1002/wps.20607

Revelle, W. (2018). psych: Procedures for Psychological, Psychometric, and Personality Research. Evanston, Illinois: Northwestern University.

Rommelse, N. N. J., Geurts, H. M., Franke, B., Buitelaar, J. K., \& Hartman, C. A. (2011). A 
review on cognitive and brain endophenotypes that may be common in autism spectrum disorder and attention-deficit/hyperactivity disorder and facilitate the search for pleiotropic genes. Neuroscience \& Biobehavioral Reviews, 35(6), 1363-1396. https://doi.org/https://doi.org/10.1016/j.neubiorev.2011.02.015

Rosseel, Y. (2012). Lavaan: An R package for structural equation modeling and more. Version 0.5-12 (BETA). Journal of Statistical Software, 48(2), 1-36.

Rotzer, S., Loenneker, T., Kucian, K., Martin, E., Klaver, P., \& von Aster, M. (2009). Dysfunctional neural network of spatial working memory contributes to developmental dyscalculia. Neuropsychologia, 47(13), 2859-2865. https://doi.org/https://doi.org/10.1016/j.neuropsychologia.2009.06.009

Rucklidge, J. J., \& Tannock, R. (2002). Neuropsychological profiles of adolescents with ADHD: effects of reading difficulties and gender. Journal of Child Psychology and Psychiatry, 43(8), 988-1003. https://doi.org/10.1111/1469-7610.00227

Schermelleh-Engel, K., Moosbrugger, H., \& Müller, H. (2003). Evaluating the fit of structural equation models: Tests of significance and descriptive goodness-of-fit measures. Methods of Psychological Research Online, 8(2), 23-74.

Siegel, L. S. (1994). Working memory and reading: A life-span perspective. International Journal of Behavioral Development, 17(1), 109-124.

Simmons, F. R., \& Singleton, C. (2008). Do weak phonological representations impact on arithmetic development? A review of research into arithmetic and dyslexia. Dyslexia, 14(2), 77-94. https://doi.org/10.1002/dys.341

Simpson-Kent, I. L., Fuhrmann, D., Bathelt, J., Achterberg, J., Borgeest, G. S., Kievit, R. A., \& Team, C. (2020). Neurocognitive reorganization between crystallized intelligence, fluid intelligence and white matter microstructure in two age-heterogeneous developmental cohorts. Developmental Cognitive Neuroscience, 41, 100743.

Snowling, M., Cain, K., Nation, K., \& Oakhill, J. (2009). Reading comprehension: nature, assessment and teaching.

Snowling, M. J., \& Hulme, C. (2012). Annual Research Review: The nature and classification of reading disorders-a commentary on proposals for DSM-5. Journal of 
Child Psychology and Psychiatry, 53(5), 593-607.

Sonuga-Barke, E., Bitsakou, P., \& Thompson, M. (2010). Beyond the Dual Pathway Model: Evidence for the Dissociation of Timing, Inhibitory, and Delay-Related Impairments in Attention-Deficit/Hyperactivity Disorder. Journal of the American Academy of Child \& Adolescent Psychiatry, 49(4), 345-355.

https://doi.org/https://doi.org/10.1016/j.jaac.2009.12.018

Sonuga-Barke, E. J. S. (2002). Psychological heterogeneity in AD/HD - a dual pathway model of behaviour and cognition. Behavioural Brain Research, 130(1), 29-36. https://doi.org/https://doi.org/10.1016/S0166-4328(01)00432-6

Sonuga-Barke, E. J. S., \& Coghill, D. (2014). The foundations of next generation attentiondeficit/hyperactivity disorder neuropsychology: building on progress during the last 30 years. Journal of Child Psychology and Psychiatry, 55(12), e1-e5. https://doi.org/10.1111/jcpp.12360

Sonuga-Barke, E. J. S., Cortese, S., Fairchild, G., \& Stringaris, A. (2016). Annual Research Review: Transdiagnostic neuroscience of child and adolescent mental disorders differentiating decision making in attention-deficit/hyperactivity disorder, conduct disorder, depression, and anxiety. Journal of Child Psychology and Psychiatry, 57(3), 321-349. https://doi.org/10.1111/jcpp.12496

St Clair-Thompson, H. L., \& Gathercole, S. E. (2006). Executive functions and achievements in school: Shifting, updating, inhibition, and working memory. Quarterly Journal of Experimental Psychology, 59(4), 745-759.

Stanovich, K. E. (1991). Cognitive science meets beginning reading. Psychological Science, $2(2), 70-83$.

Steenkamp, J.-B. E. M., \& Baumgartner, H. (1998). Assessing Measurement Invariance in Cross-National Consumer Research. Journal of Consumer Research, 25(1), 78-90. https://doi.org/10.1086/209528

Stimulant drugs and ADHD: Basic and clinical neuroscience. (2001). In M. V Solanto, A. F. T. Arnsten, \& F. X. Castellanos (Eds.), Stimulant drugs and ADHD: Basic and clinical neuroscience. New York, NY, US: Oxford University Press. 
Stuebing, K. K., Fletcher, J. M., Branum-Martin, L., Francis, D. J., \& VanDerHeyden, A. (2012). Evaluation of the Technical Adequacy of Three Methods for Identifying Specific Learning Disabilities Based on Cognitive Discrepancies. School Psychology Review, 41(1), 3-22. https://doi.org/10.1080/02796015.2012.12087373

Stuebing, K. K., Fletcher, J. M., LeDoux, J. M., Lyon, G. R., Shaywitz, S. E., \& Shaywitz, B. A. (2002). Validity of IQ-discrepancy classifications of reading disabilities: A metaanalysis. American Educational Research Journal, 39(2), 469-518.

Swanson, H. L., \& Ashbaker, M. H. (2000). Working memory, short-term memory, speech rate, word recognition and reading comprehension in learning disabled readers: Does the executive system have a role? Intelligence, 28(1), 1-30.

Swanson, H. L., \& Jerman, O. (2006). Math disabilities: A selective meta-analysis of the literature. Review of Educational Research, 76(2), 249-274.

Swanson, H. L., Zheng, X., \& Jerman, O. (2009). Working memory, short-term memory, and reading disabilities: A selective meta-analysis of the literature. Journal of Learning Disabilities, 42(3), 260-287.

Szucs, D., Devine, A., Soltesz, F., Nobes, A., \& Gabriel, F. (2013). Developmental dyscalculia is related to visuo-spatial memory and inhibition impairment. Cortex, 49(10), 2674-2688. https://doi.org/https://doi.org/10.1016/j.cortex.2013.06.007

Team, R. C. (2018). R Foundation for Statistical Computing; Vienna, Austria: 2015. R: A Language and Environment for Statistical Computing, 2013.

Tenenbaum, R. B., Musser, E. D., Morris, S., Ward, A. R., Raiker, J. S., Coles, E. K., \& Pelham, W. E. (2019). Response Inhibition, Response Execution, and Emotion Regulation among Children with Attention-Deficit/Hyperactivity Disorder. Journal of Abnormal Child Psychology, 47(4), 589-603. https://doi.org/10.1007/s10802-018-0466$\mathrm{y}$

Titov, N., Dear, B. F., Schwencke, G., Andrews, G., Johnston, L., Craske, M. G., \& McEvoy, P. (2011). Transdiagnostic internet treatment for anxiety and depression: A randomised controlled trial. Behaviour Research and Therapy, 49(8), 441-452. https://doi.org/https://doi.org/10.1016/j.brat.2011.03.007 
Tolar, T. D., Fuchs, L., Fletcher, J. M., Fuchs, D., \& Hamlett, C. L. (2014). Cognitive Profiles of Mathematical Problem Solving Learning Disability for Different Definitions of Disability. Journal of Learning Disabilities, 49(3), 240-256. https://doi.org/10.1177/0022219414538520

van de Schoot, R., Kluytmans, A., Tummers, L., Lugtig, P., Hox, J., \& Muthén, B. (2013). Facing off with Scylla and Charybdis: a comparison of scalar, partial, and the novel possibility of approximate measurement invariance. Frontiers in Psychology, 4. https://doi.org/10.3389/fpsyg.2013.00770

Van Der Maas, H. L. J., Dolan, C. V, Grasman, R. P. P. P., Wicherts, J. M., Huizenga, H. M., \& Raijmakers, M. E. J. (2006). A dynamical model of general intelligence: the positive manifold of intelligence by mutualism. Psychological Review, 113(4), 842.

von Aster, M., Schweiter, M., \& Weinhold Zulauf, M. (2007). Rechenstörungen bei Kindern. Zeitschrift Für Entwicklungspsychologie Und Pädagogische Psychologie, 39(2), 85-96.

Vukovic, R. K., \& Lesaux, N. K. (2013). The language of mathematics: Investigating the ways language counts for children's mathematical development. Journal of Experimental Child Psychology, 115(2), 227-244. https://doi.org/https://doi.org/10.1016/j.jecp.2013.02.002

W., C. H., M., A. S., \& Ellis, W. S. (2006). Language Deficits in Poor Comprehenders: A Case for the Simple View of Reading. Journal of Speech, Language, and Hearing Research, 49(2), 278-293. https://doi.org/10.1044/1092-4388(2006/023)

Wagner, R. K., Torgesen, J. K., \& Rashotte, C. A. (1994). Development of reading-related phonological processing abilities: New evidence of bidirectional causality from a latent variable longitudinal study. Developmental Psychology, 30(1), 73.

Wechsler, D. (2005). Wechsler Individual Achievement Test (WIAT-II UK): Harcourt Assessment. London, UK: Pearson Assessment.

Wechsler, D. (2011). WASI-II: Wechsler abbreviated scale of intelligence. PsychCorp.

Willcutt, E. G., Betjemann, R. S., McGrath, L. M., Chhabildas, N. A., Olson, R. K., DeFries, J. C., \& Pennington, B. F. (2010). Etiology and neuropsychology of comorbidity between RD and ADHD: The case for multiple-deficit models. Cortex, 46(10), 1345- 
1361.

Willcutt, E. G., Pennington, B. F., Boada, R., Ogline, J. S., Tunick, R. A., Chhabildas, N. A., \& Olson, R. K. (2001). A comparison of the cognitive deficits in reading disability and attention-deficit/hyperactivity disorder. Journal of Abnormal Psychology, Vol. 110, pp. 157-172. https://doi.org/10.1037/0021-843X.110.1.157

Willcutt, E. G., Petrill, S. A., Wu, S., Boada, R., DeFries, J. C., Olson, R. K., \& Pennington, B. F. (2013). Comorbidity Between Reading Disability and Math Disability: Concurrent Psychopathology, Functional Impairment, and Neuropsychological Functioning. Journal of Learning Disabilities, 46(6), 500-516. https://doi.org/10.1177/0022219413477476

Woodcock, R. W., McGrew, K. S., \& Mather, N. (2007). Woodcock-Johnson Tests of Achievement, (WJ-III ACH). Rolling Meadows, IL: Riverside.

Yeniad, N., Malda, M., Mesman, J., van IJzendoorn, M. H., \& Pieper, S. (2013). Shifting ability predicts math and reading performance in children: A meta-analytical study. Learning and Individual Differences, 23, 1-9.

Young, C. J., Levine, S. C., \& Mix, K. S. (2018). The connection between spatial and mathematical ability across development. Frontiers in Psychology, 9, 755.

Zhao, Y., \& Castellanos, F. X. (2016). Annual Research Review: Discovery science strategies in studies of the pathophysiology of child and adolescent psychiatric disorders - promises and limitations. Journal of Child Psychology and Psychiatry, 57(3), 421-439. https://doi.org/10.1111/jcpp.12503 


\section{FIGURES}

\section{Figure 1}

Consort Diagram Showing CALM Study Referral Routes

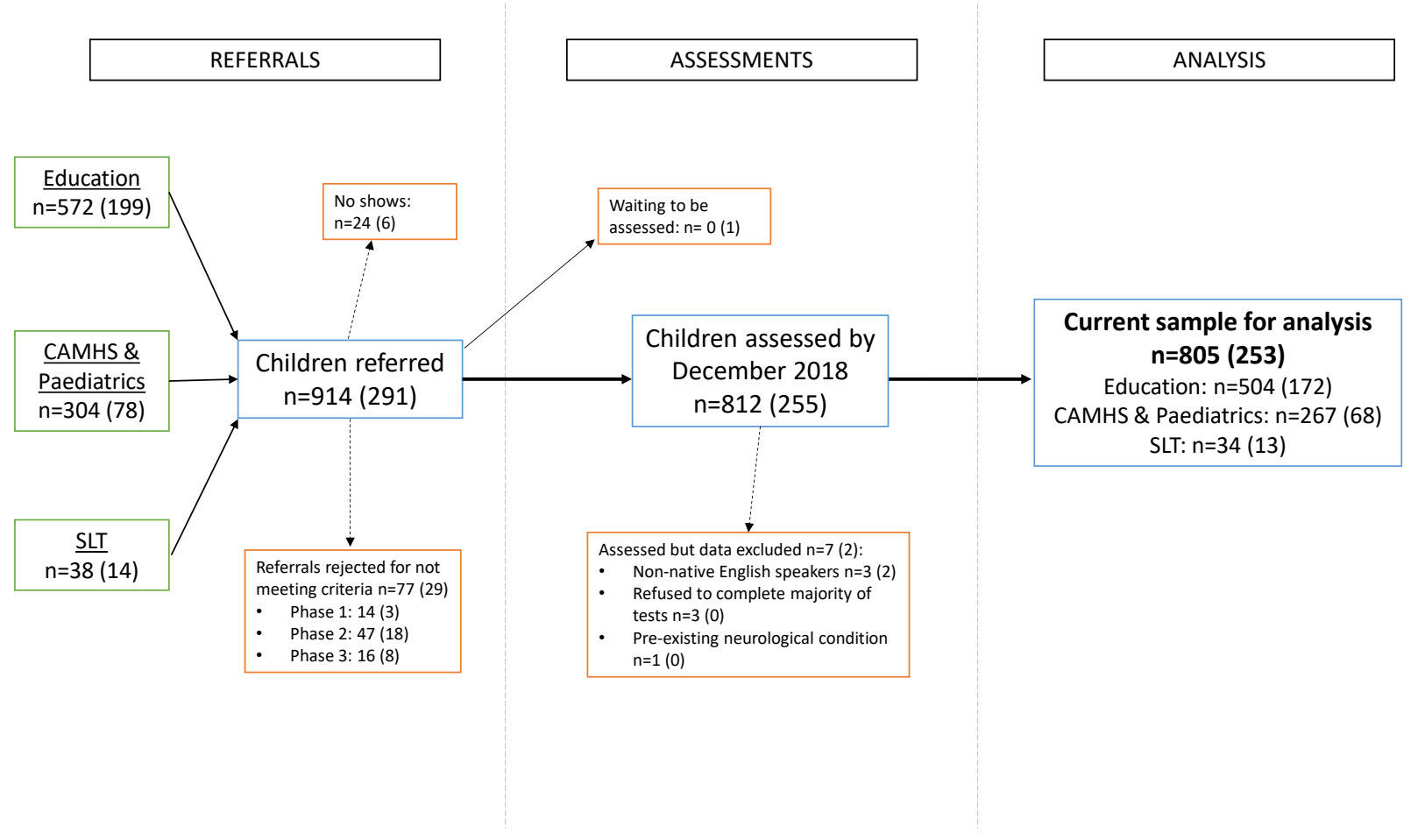

Note. $\mathrm{N}$ (female) 


\section{Figure 2}

Three-Factor Confirmatory Factor Analysis Model for the Whole CALM sample (All Ages)

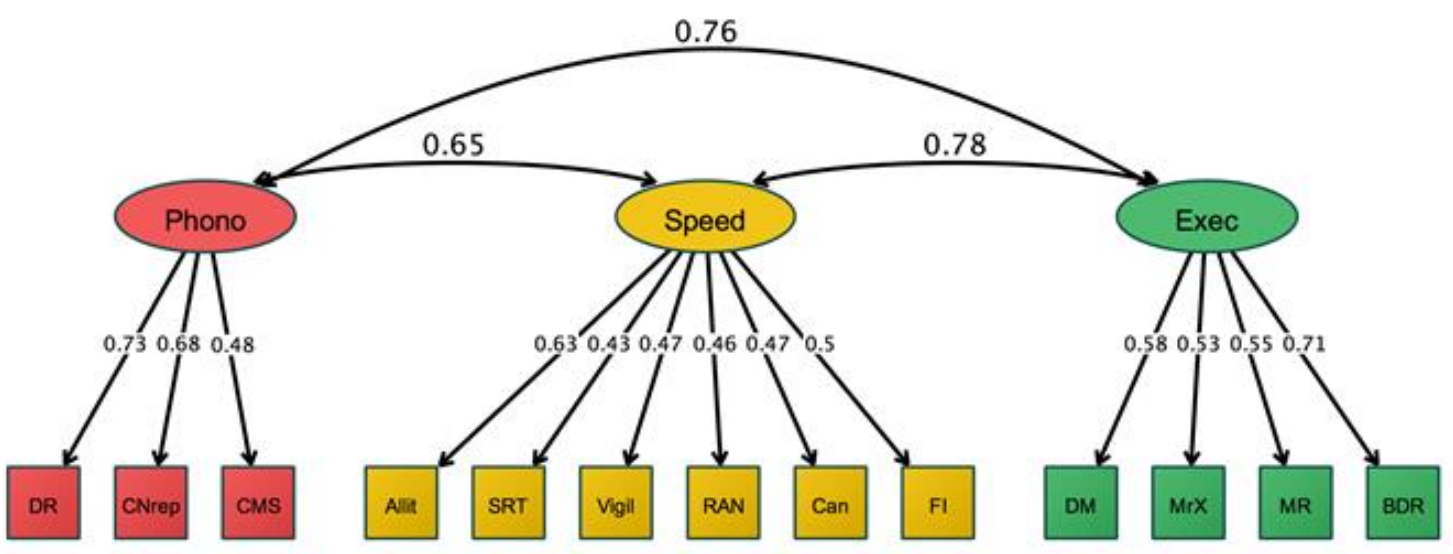

Note. Latent variables phonological processing (phono), speed, and executive functions (exec) are represented in ovals. Cognitive measures are shown as observed variables in squares. Variable names are: $\mathrm{CNrep}=$ Nonword Repetition, $\mathrm{DR}=$ Digit Recall, $\mathrm{CMS}=$ Delayed Story Recall, SRT $=$ Simple Reaction Time, Allit $=$ Alliteration, RAN $=$ Rapid Automatic Naming, FI = Following Instructions, $\mathrm{Can}=$ Cancellation, MR= Matrix Reasoning, $\mathrm{DM}=$ Dot Matrix, $\mathrm{BDR}=$ Backward Digit Recall, $\mathrm{MrX}=\mathrm{Mr} \mathrm{X}$. Parameter estimates are fully standardized. Residual variances are freely estimated but not shown for visual clarity. 


\section{Figure 3}

Path Models Predicting Learning from Cognitive Factors for the Whole Sample (All Ages)

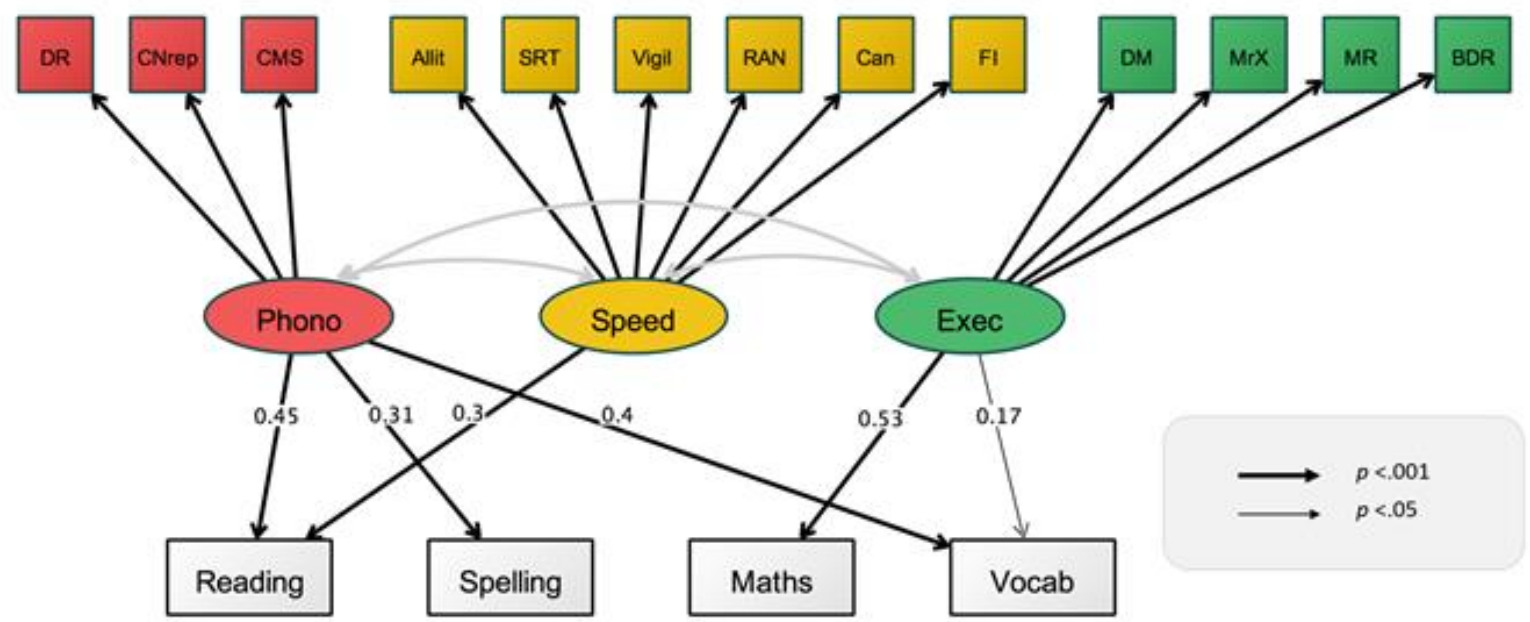

Note. $\mathrm{N}=805$; Learning outcomes (reading, spelling, maths and vocabulary) are regressed on phonological processing, speed, and executive factors. Parameter estimates are fully standardized. Factor loadings and covariances are not shown for simplicity. Variable names are: CNrep $=$ Nonword Repetition, DR $=$ Digit Recall, CMS $=$ Delayed Story Recall, SRT = Simple Reaction Time, Allit $=$ Alliteration, $\mathrm{RAN}=$ Rapid Automatic Naming, FI $=$ Following Instructions, $\mathrm{Can}=$ Cancellation, $\mathrm{MR}=$ Matrix Reasoning, $\mathrm{DM}=$ Dot Matrix, $\mathrm{BDR}=$ Backward Digit Recall, $\mathrm{MrX}=\mathrm{Mr} \mathrm{X}$. Residual variances are freely estimated but not shown for visual clarity. 


\section{Figure 4}

Three-Factor Confirmatory Factor Analysis for Children Aged 8 Years and Older

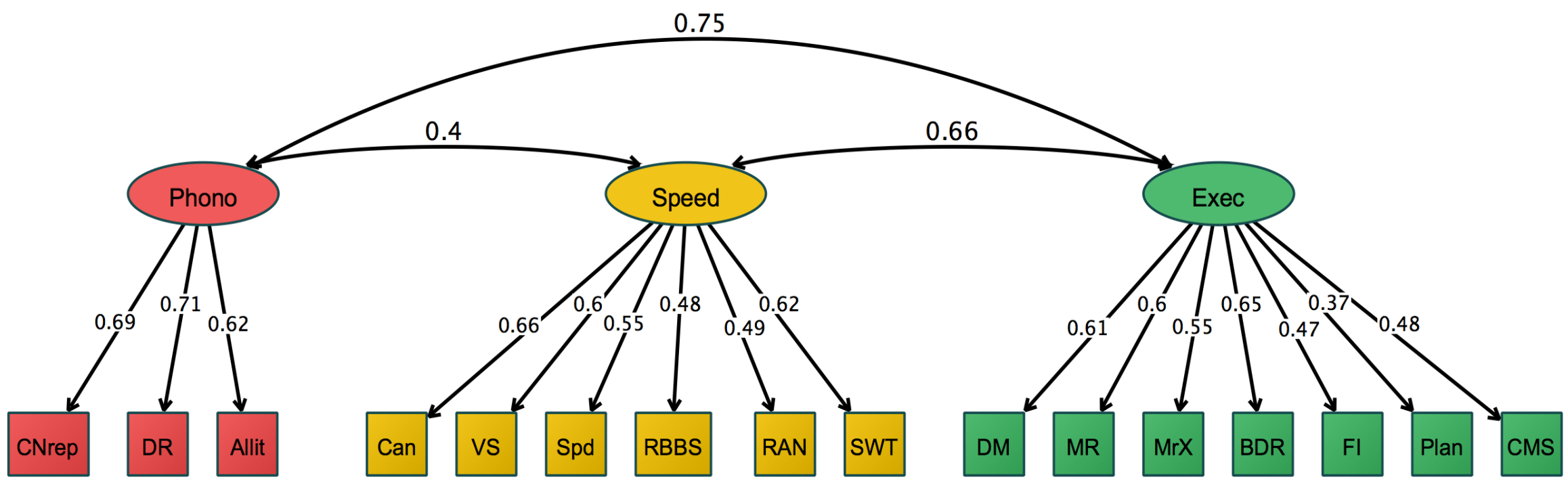

Note. Latent variables executive functions (exec), processing speed (speed), and phonological processing (phono) are represented in ovals.

Cognitive measures are shown as observed variables in squares. DM = Dot matrix, BDR = Backward Digit Recall, MrX = Mr X, FI = Following Instructions, CMS = Delayed Story Recall, Plan = planning, MR= Matrix Reasoning, RAN = Rapid Automatic Naming, VS = Visual Scanning, Spd = Motor Speed, SWT = Number-Letter Switching, Can= Cancellation, RBBS= Reds, Blues, Bags and Shoes switching, Allit $=$ Alliteration, CNrep = Nonword Repetition, DR = Digit Recall. Parameter estimates are fully standardized. Residual variances are freely estimated but not shown for visual clarity. 


\section{Figure 5}

Path Models Predicting Learning from Cognitive Factors for Children 8 Years and Older

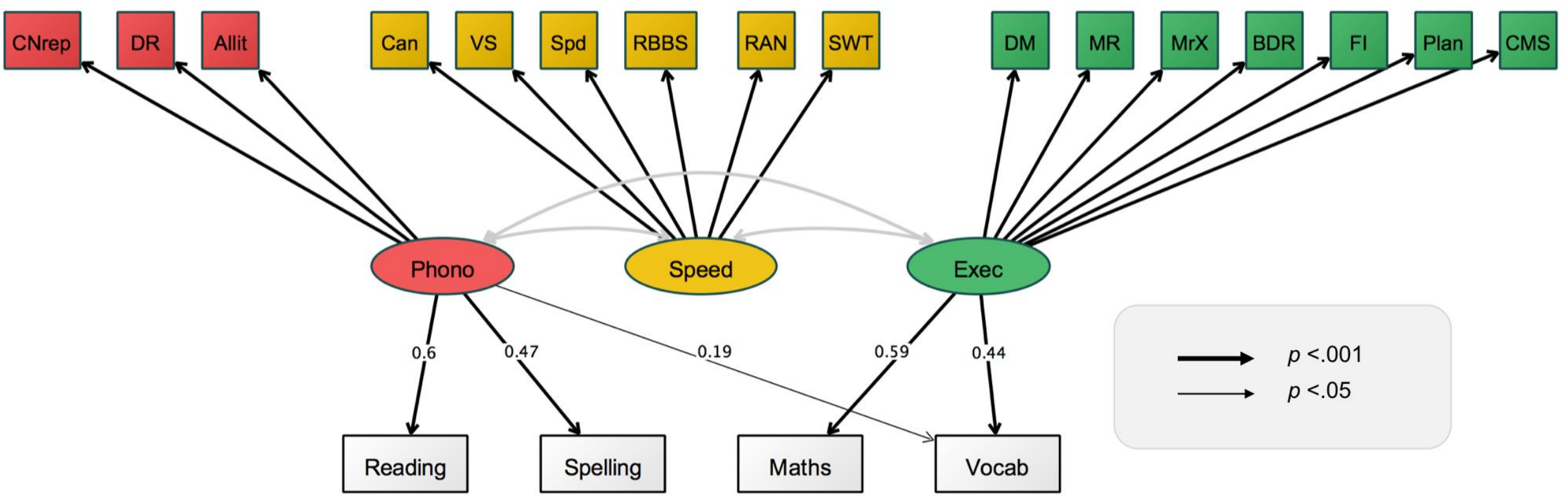

Note. $\mathrm{N}=566$; Learning outcomes (reading, spelling, maths and vocabulary) are regressed on phonological processing, speed, and executive factors. Parameter estimates are fully standardized. Factor loadings are not shown for simplicity. 


\section{TABLES}

\section{Table 1}

Diagnostic Status of all Children in the CALM Sample

\begin{tabular}{|c|c|}
\hline Diagnosis & $N$ (female) \\
\hline ADHD or possible ADHD & $255(61)$ \\
\hline Dyslexia & $47(15)$ \\
\hline Dyspraxia & $21(7)$ \\
\hline Dysgraphia & $1(0)$ \\
\hline Dyscalculia & $2(2)$ \\
\hline FASD & $6(4)$ \\
\hline Global delay & $10(5)$ \\
\hline Depression & $3(3)$ \\
\hline Anxiety (inc. social anxiety) & $9(4)$ \\
\hline Autism & $57(7)$ \\
\hline PDA & $1(1)$ \\
\hline Tourettes & $5(1)$ \\
\hline DAMP & $4(1)$ \\
\hline OCD & $5(4)$ \\
\hline Sensory processing disorder & $3(1)$ \\
\hline Language disorder (inc. SLI) & $2(1)$ \\
\hline Conduct disorder & $1(0)$ \\
\hline ODD & $3(1)$ \\
\hline Epilepsy & $4(2)$ \\
\hline Anorexia & $1(1)$ \\
\hline Speech \& language therapy & $160(51)$ \\
\hline No diagnosis & $484(165)$ \\
\hline
\end{tabular}

Note. Total $\mathrm{N}$ is higher than the sample size as some children had multiple diagnoses 
Table 2 Descriptive Statistics for All Children and Children 8 Years and Older

\begin{tabular}{|c|c|c|c|c|c|c|c|c|c|c|c|c|}
\hline \multirow[b]{3}{*}{ Measurement } & \multicolumn{12}{|c|}{ Group } \\
\hline & \multicolumn{6}{|c|}{ All Ages } & \multicolumn{6}{|c|}{8 years +} \\
\hline & $\mathrm{n}$ & $\min$ & $\max$ & $M$ & $S D$ & $S E$ & $\mathrm{n}$ & $\min$ & $\max$ & $M$ & $S D$ & $S E$ \\
\hline \multicolumn{13}{|l|}{ Phonological Processing } \\
\hline alliteration & 788 & 69 & 107 & 91.31 & 10.12 & 0.36 & 559 & 70 & 101 & 92.63 & 9.51 & 0.4 \\
\hline rapid naming & 786 & 0 & 131 & 88.68 & 15.14 & 0.54 & 554 & 0 & 131 & 90.6 & 14.7 & 0.62 \\
\hline nonword repetition & 481 & 45 & 125 & 82.41 & 20.62 & 0.94 & 351 & 45 & 123 & 80.55 & 21.6 & 1.15 \\
\hline \multicolumn{13}{|l|}{ Processing Speed } \\
\hline visual scanning & - & - & - & - & - & - & 478 & 1 & 16 & 9.32 & 3.41 & 0.16 \\
\hline simple reaction time & 739 & 1 & 19 & 7.8 & 4.06 & 0.15 & 524 & 1 & 19 & 8.11 & 4.18 & 0.18 \\
\hline \multicolumn{13}{|l|}{ WM/STM } \\
\hline digit recall & 801 & 60 & 149 & 92.63 & 15.41 & 0.54 & 564 & 60 & 149 & 91.64 & 15.62 & 0.66 \\
\hline dot matrix & 799 & 47 & 141.2 & 90.63 & 14.98 & 0.53 & 564 & 47 & 141.2 & 90.01 & 15.62 & 0.66 \\
\hline backward digit & 780 & 58 & 137 & 91.53 & 12.62 & 0.45 & 562 & 58 & 137 & 91.44 & 11.48 & 0.48 \\
\hline $\mathrm{mrX}$ & 795 & 61 & 148 & 97.38 & 15.35 & 0.54 & 563 & 61.7 & 144 & 95.9 & 14.46 & 0.61 \\
\hline following instructions & 750 & 9.6 & 18.58 & 0 & 3.64 & 0.13 & 530 & -9.19 & 18.95 & 0 & 3.71 & 0.16 \\
\hline \multicolumn{13}{|l|}{ Episodic Memory } \\
\hline delayed story recall & 775 & 1 & 19 & 7.88 & 3.3 & 0.12 & 550 & 1 & 18 & 7.7 & 3.23 & 0.14 \\
\hline \multicolumn{13}{|l|}{ Attention } \\
\hline vigil & 748 & 3 & 19 & 8.01 & 3.29 & 0.12 & 528 & 3 & 19 & 8.26 & 3.3 & 0.14 \\
\hline cancellation & 771 & 1 & 19 & 10.17 & 3.31 & 0.12 & 552 & 1 & 19 & 10.32 & 3.26 & 0.14 \\
\hline switching & - & - & - & - & - & - & 516 & 1 & 19 & 7.72 & 3.49 & 0.15 \\
\hline \multicolumn{13}{|l|}{ Executive Functions } \\
\hline planning & - & - & - & - & - & - & 441 & 1 & 19 & 9.43 & 2.52 & 0.12 \\
\hline number letter switching & - & - & - & - & - & - & 423 & 1 & 15 & 6.28 & 3.87 & 0.19 \\
\hline \multicolumn{13}{|l|}{ Learning Measures } \\
\hline spelling & 778 & 32 & 131 & 84.17 & 14.01 & 0.5 & 553 & 46 & 131 & 83.72 & 14.01 & 0.6 \\
\hline maths & 789 & 42 & 156 & 84.9 & 16.43 & 0.58 & 555 & 45 & 156 & 84.13 & 17.06 & 0.72 \\
\hline vocabulary & 796 & 20 & 145 & 97.58 & 15.72 & 0.56 & 561 & 20 & 145 & 96.83 & 16.13 & 0.68 \\
\hline
\end{tabular}


Table 3 Descriptive Statistics for Children with and without ADHD, All Ages

Note. $\mathrm{p}<.05^{*}, \mathrm{p}<.01^{* *}$. WM=Working Memory; STM-Short-term Memory. Residual scores were calculated for Following Instructions.

\begin{tabular}{|c|c|c|c|c|c|c|c|c|c|c|c|c|c|c|c|}
\hline \multirow[b]{3}{*}{ Measurement } & \multicolumn{12}{|c|}{ Group } & \multirow{2}{*}{\multicolumn{3}{|c|}{ Group Comparisons }} \\
\hline & \multicolumn{6}{|c|}{ Children without ADHD $(\mathrm{N}=550)$} & \multicolumn{6}{|c|}{ Children with ADHD $(\mathrm{N}=255)$} & & & \\
\hline & $\mathrm{n}$ & $\min$ & $\max$ & $M$ & $S D$ & $S E$ & $\mathrm{n}$ & $\min$ & $\max$ & $M$ & $S D$ & $S E$ & $t$ & $p$ & $d$ \\
\hline Phonological Processing & & & & & & & & & & & & & & & \\
\hline alliteration & 539 & 69 & 107 & 90.91 & 10.33 & 0.45 & 249 & 70 & 103 & 92.20 & 9.61 & 0.45 & -1.66 & .096 & -0.13 \\
\hline rapid naming & 541 & 69 & 131 & 88.00 & 14.78 & 0.64 & 245 & 0 & 131 & 90.18 & 15.84 & 0.64 & -1.87 & .061 & -0.14 \\
\hline nonword repetition & 263 & 45 & 125 & 81.35 & 19.6 & 1.21 & 218 & 45 & 123 & 83.7 & 21.76 & 1.21 & -1.25 & .213 & -0.11 \\
\hline $\begin{array}{l}\text { Processing Speed } \\
\text { simple reaction time } \\
\text { WM/STM }\end{array}$ & 509 & 1 & 19 & 7.77 & 4.01 & 0.18 & 230 & 1 & 19 & 7.85 & 4.19 & 0.28 & -0.25 & .804 & -0.02 \\
\hline digit recall & 547 & 60 & 139 & 93.05 & 15.35 & 0.66 & 254 & 60 & 149 & 91.72 & 15.54 & 0.97 & 1.14 & .256 & 0.08 \\
\hline dot matrix & 545 & 47 & 141.2 & 91.20 & 14.70 & 0.63 & 254 & 56 & 135 & 89.4 & 15.53 & 0.97 & 1.58 & .114 & 0.12 \\
\hline backward digit & 530 & 58 & 135 & 91.62 & 12.58 & 0.55 & 250 & 64 & 137 & 91.35 & 12.72 & 0.8 & 0.28 & .783 & 0.02 \\
\hline $\mathrm{mrX}$ & 543 & 61.7 & 148 & 97.74 & 15.54 & 0.67 & 252 & 61 & 134 & 96.6 & 14.93 & 0.94 & 0.98 & .330 & 0.07 \\
\hline following instructions & 507 & -9.6 & 16.23 & -0.14 & 3.54 & 0.16 & 243 & -9.11 & 18.58 & 0.28 & 3.83 & 0.25 & -1.48 & .140 & -0.12 \\
\hline $\begin{array}{l}\text { Episodic Memory } \\
\text { delayed story recall } \\
\text { Attention }\end{array}$ & 532 & 1 & 19 & 7.98 & 3.34 & 0.14 & 243 & 1 & 17 & 7.66 & 3.21 & 0.21 & 1.25 & .212 & 0.10 \\
\hline vigil & 517 & 3 & 19 & 7.94 & 3.25 & 0.14 & 231 & 3 & 16 & 8.16 & 3.39 & 0.22 & -0.84 & .403 & -0.07 \\
\hline cancellation & 523 & 1 & 19 & 9.95 & 3.19 & 0.14 & 248 & 1 & 19 & 10.62 & 3.5 & 0.22 & -2.66 & $.008 * *$ & -0.21 \\
\hline $\begin{array}{l}\text { Executive Functions } \\
\text { matrix reasoning }\end{array}$ & 549 & 20 & 80 & 42.51 & 9.21 & 0.39 & 255 & 23 & 73 & 44.18 & 10.21 & 0.64 & -2.33 & $.021 *$ & -0.17 \\
\hline $\begin{array}{l}\text { Learning Measures } \\
\text { reading }\end{array}$ & 539 & 40 & 140 & 85.97 & 16.72 & 0.72 & 246 & 49 & 134 & 89.26 & 17.01 & 1.08 & -2.54 & $.011 *$ & -0.20 \\
\hline spelling & 530 & 32 & 123 & 83.38 & 13.53 & 0.59 & 248 & 48 & 131 & 85.88 & 14.85 & 0.94 & -2.33 & $.020 *$ & -0.18 \\
\hline maths & 537 & 46 & 153 & 84.18 & 15.36 & 0.66 & 252 & 42 & 156 & 86.46 & 18.44 & 1.16 & -1.82 & .068 & -0.14 \\
\hline vocabulary & 543 & 20 & 145 & 97.08 & 15.96 & 0.68 & 253 & 44 & 139 & 98.64 & 15.17 & 0.95 & -1.30 & .194 & -0.10 \\
\hline
\end{tabular}




\section{Table 4}

Path Models for Cognitive Factors Predicting Learning Outcomes in Children with and without ADHD, All Ages

\begin{tabular}{|c|c|c|c|c|c|c|c|c|c|c|}
\hline \multirow[b]{3}{*}{ Estimates - free models } & \multicolumn{10}{|c|}{ Group } \\
\hline & \multicolumn{5}{|c|}{ Children without ADHD $(n=550)$} & \multicolumn{5}{|c|}{ Children with ADHD $(n=255)$} \\
\hline & Estimate & $S E$ & $z$ & $p$ & $\begin{array}{c}\text { fully } \\
\text { standardized } \\
\text { estimate }\end{array}$ & Estimate & $S E$ & $z$ & $p$ & $\begin{array}{c}\text { fully } \\
\text { standardized } \\
\text { estimate }\end{array}$ \\
\hline \multicolumn{11}{|l|}{ Reading } \\
\hline reading $\sim$ phono & 0.909 & 0.142 & 6.38 & $<.001 * *$ & 0.517 & 0.574 & 0.183 & 3.132 & $.002 * *$ & 0.329 \\
\hline reading $\sim$ speed & 0.463 & 0.256 & 1.81 & .071 & 0.152 & 1.823 & 0.362 & 5.038 & $<.001 * *$ & 0.571 \\
\hline reading executive & -0.154 & 0.246 & -0.624 & .533 & -0.07 & -0.546 & 0.331 & -1.652 & .098 & -0.246 \\
\hline$R^{2}$ & 0.338 & & & & & 0.400 & & & & \\
\hline \multicolumn{11}{|l|}{ Maths } \\
\hline maths phono & 0.085 & 0.125 & 0.675 & .499 & 0.052 & -0.118 & 0.160 & -0.738 & .460 & -0.063 \\
\hline maths speed & 0.221 & 0.236 & 0.936 & .350 & 0.079 & 0.427 & 0.363 & 1.177 & .239 & 0.124 \\
\hline maths executive & 0.961 & 0.229 & 4.198 & $<.001 * *$ & 0.476 & 1.503 & 0.346 & 4.347 & $<.001 * *$ & 0.629 \\
\hline$R^{2}$ & 0.359 & & & & & 0.473 & & & & \\
\hline Estimates - constrained models & Estimate & $S E$ & $z$ & $p$ & $\begin{array}{c}\text { fully } \\
\text { standardized } \\
\text { estimate }\end{array}$ & Estimate & $S E$ & $z$ & $p$ & $\begin{array}{c}\text { fully } \\
\text { standardized } \\
\text { estimate }\end{array}$ \\
\hline \multicolumn{11}{|l|}{ Spelling } \\
\hline spelling phono & 0.458 & 0.108 & 4.232 & $<.001 * *$ & 0.313 & 0.458 & 0.108 & 4.232 & $<.001 * *$ & 0.318 \\
\hline spelling speed & 0.286 & 0.182 & 1.569 & .117 & 0.113 & 0.286 & 0.182 & 1.569 & .117 & 0.108 \\
\hline spelling executive & 0.159 & 0.181 & 0.877 & .380 & 0.087 & 0.159 & 0.181 & 0.877 & .380 & 0.086 \\
\hline$R^{2}$ & 0.242 & & & & & 0.241 & & & & \\
\hline \multicolumn{11}{|l|}{ Vocab } \\
\hline vocab phono & 0.661 & 0.112 & 5.891 & $<.001 * *$ & 0.398 & 0.661 & 0.112 & 5.891 & $<.001 * *$ & 0.414 \\
\hline vocab speed & 0.098 & 0.217 & 0.452 & .651 & 0.034 & 0.098 & 0.217 & 0.452 & .651 & 0.034 \\
\hline vocab executive & 0.374 & 0.202 & 1.85 & .064 & 0.181 & 0.374 & 0.202 & 1.85 & .064 & 0.184 \\
\hline$R^{2}$ & 0.355 & & & & & 0.375 & & & & \\
\hline
\end{tabular}

Note. $*$ indicates $\mathrm{p}<.05$. $* *$ indicates $\mathrm{p}<.01$. Phono $=$ phonological processing; Vocab $=$ Vocabulary. 


\section{Table 5}

Descriptive Statistics for Children with and without ADHD, 8 Years and Older

\begin{tabular}{|c|c|c|c|c|c|c|c|c|c|c|c|c|c|c|c|}
\hline \multirow[b]{3}{*}{ Measurement } & \multicolumn{12}{|c|}{ Group } & \multirow{2}{*}{\multicolumn{3}{|c|}{ Group Comparisons }} \\
\hline & \multicolumn{6}{|c|}{ Children without ADHD $(n=374)$} & \multicolumn{6}{|c|}{ Children with ADHD (n=192) } & & & \\
\hline & $\mathrm{n}$ & $\min$ & $\max$ & $M$ & $S D$ & $S E$ & $\mathrm{n}$ & $\min$ & $\max$ & $M$ & $S D$ & $S E$ & $t$ & $p$ & $d$ \\
\hline \multicolumn{16}{|l|}{ Phonological Processing } \\
\hline alliteration & 372 & 70 & 101 & 92.50 & 9.51 & 0.49 & 187 & 70 & 101 & 92.89 & 9.53 & 0.70 & -0.46 & .642 & -0.04 \\
\hline rapid naming & 370 & 69 & 131 & 89.98 & 14.28 & 0.74 & 184 & 0 & 131 & 91.85 & 15.47 & 1.14 & -1.41 & .160 & -0.12 \\
\hline nonword repetition & 185 & 45 & 119 & 79.88 & 20.53 & 1.51 & 166 & 45 & 123 & 81.30 & 22.77 & 1.77 & -0.61 & .540 & -0.07 \\
\hline \multicolumn{16}{|l|}{ Processing Speed } \\
\hline visual scanning & 303 & 1 & 15 & 9.45 & 3.21 & 0.18 & 175 & 1 & 16 & 9.11 & 3.72 & 0.28 & 1.05 & .293 & 0.10 \\
\hline motor speed & 298 & 1 & 14 & 9.89 & 2.84 & 0.16 & 175 & 1 & 14 & 10.49 & 2.64 & 0.20 & -2.27 & $.023 *$ & -0.21 \\
\hline simple reaction time & 353 & 1 & 19 & 8.09 & 4.11 & 0.22 & 171 & 1 & 19 & 8.13 & 4.31 & 0.33 & -0.11 & .916 & -0.01 \\
\hline \multicolumn{16}{|l|}{ WM/STM } \\
\hline digit recall & 372 & 60 & 139 & 92.06 & 15.46 & 0.8 & 192 & 60 & 149 & 90.82 & 15.92 & 1.15 & 0.89 & .373 & 0.08 \\
\hline dot matrix & 372 & 47 & 141.2 & 90.36 & 15.36 & 0.80 & 192 & 56 & 135 & 89.34 & 16.11 & 1.16 & 0.74 & .462 & 0.06 \\
\hline backward digit & 371 & 58 & 132 & 91.32 & 11.4 & 0.59 & 191 & 70 & 137 & 91.67 & 11.67 & 0.84 & -0.34 & .737 & -0.03 \\
\hline $\mathrm{mrX}$ & 372 & 61.7 & 144 & 95.98 & 14.39 & 0.75 & 191 & 62 & 134 & 95.74 & 14.64 & 1.06 & 0.19 & .851 & 0.02 \\
\hline following instructions & 346 & -9.19 & 16.25 & -0.17 & 3.55 & 0.19 & 184 & -8.81 & 18.95 & 0.32 & 3.98 & 0.29 & -1.45 & .148 & -0.13 \\
\hline \multicolumn{16}{|l|}{ Episodic Memory } \\
\hline delayed story recall & 366 & 1 & 18 & 7.80 & 3.22 & 0.17 & 184 & 1 & 17 & 7.52 & 3.26 & 0.24 & 0.94 & .350 & 0.08 \\
\hline \multicolumn{16}{|l|}{ Attention } \\
\hline vigil & 354 & 3 & 19 & 8.14 & 3.23 & 0.17 & 174 & 3 & 16 & 8.50 & 3.44 & 0.26 & -1.17 & .244 & -0.10 \\
\hline cancellation & 365 & 1 & 19 & 10.10 & 3.09 & 0.16 & 187 & 1 & 19 & 10.75 & 3.54 & 0.26 & -2.25 & $.024 *$ & -0.19 \\
\hline switching (RBBS) & 344 & 1 & 19 & 7.53 & 3.49 & 0.19 & 172 & 1 & 16 & 8.09 & 3.49 & 0.27 & -1.74 & .082 & -0.15 \\
\hline \multicolumn{16}{|l|}{ Executive Functions } \\
\hline matrix reasoning & 374 & 20 & 80 & 41.92 & 9.78 & 0.51 & 192 & 23 & 73 & 43.38 & 10.56 & 0.76 & -1.63 & .104 & -0.14 \\
\hline planning & 270 & 1 & 19 & 9.32 & 2.45 & 0.15 & 171 & 3 & 16 & 9.59 & 2.62 & 0.20 & -1.09 & .273 & -0.10 \\
\hline number letter switching & 265 & 1 & 15 & 5.92 & 3.84 & 0.24 & 158 & 1 & 15 & 6.88 & 3.85 & 0.31 & -2.49 & $.013 *$ & -0.24 \\
\hline $\begin{array}{l}\text { Learning Measures } \\
\text { reading }\end{array}$ & 370 & 40 & 121 & 85.95 & 16.63 & 0.86 & 186 & 49 & 129 & 89.88 & 16.08 & 1.18 & -2.66 & $.008 * *$ & -0.23 \\
\hline
\end{tabular}


COGNITIVE DIMENSIONS OF LEARNING

\begin{tabular}{|c|c|c|c|c|c|c|c|c|c|c|c|c|c|c|c|}
\hline spelling & 367 & 46 & 119 & 82.77 & 13.38 & 0.7 & 186 & 48 & 131 & 85.58 & 15.04 & 1.10 & -2.23 & $.026^{*}$ & -0.19 \\
\hline maths & 366 & 46 & 153 & 83.17 & 16.05 & 0.84 & 189 & 45 & 156 & 85.99 & 18.77 & 1.37 & -1.85 & .064 & -0.16 \\
\hline vocabulary & 370 & 20 & 145 & 96.22 & 16.63 & 0.86 & 191 & 44 & 139 & 98.01 & 15.09 & 1.09 & -1.25 & .213 & -0.11 \\
\hline
\end{tabular}

Note. $\mathrm{p}<.05^{*} ; \mathrm{p}<.01^{* *}, \mathrm{WM}=$ Working Memory; STM=Short-term Memory; RBBS=Reds, Blues, Bags and Shoes. 
Table 6 Path Models Predicting Learning from Cognition in Children with and without ADHD, 8 Years and Older

\begin{tabular}{|c|c|c|c|c|c|c|c|c|c|c|}
\hline \multirow[b]{3}{*}{$\begin{array}{l}\text { Estimates - constrained } \\
\text { models }\end{array}$} & \multicolumn{10}{|c|}{ Group } \\
\hline & \multicolumn{5}{|c|}{ Children without ADHD $(n=374)$} & \multicolumn{5}{|c|}{ Children with ADHD (n=192) } \\
\hline & Estimate & $S E$ & $z$ & $p$ & $\begin{array}{l}\text { Fully Standardized } \\
\text { Estimate }\end{array}$ & Estimate & $S E$ & $z$ & $p$ & $\begin{array}{c}\text { Fully Standardized } \\
\text { Estimate }\end{array}$ \\
\hline \multicolumn{11}{|l|}{ Reading } \\
\hline reading phono & 0.761 & 0.095 & 7.989 & $<.001 * *$ & 0.590 & 0.761 & 0.095 & 7.989 & $<.001 * *$ & 0.626 \\
\hline reading speed & 0.597 & 0.528 & 1.13 & .259 & 0.065 & 0.597 & 0.528 & 1.13 & .259 & 0.072 \\
\hline $\begin{array}{l}\text { reading executive } \\
R^{2} \\
\text { Spelling }\end{array}$ & $\begin{array}{c}-0.073 \\
.353\end{array}$ & 0.188 & 0.386 & .700 & -0.037 & $\begin{array}{c}-0.073 \\
.400\end{array}$ & 0.188 & 0.386 & .700 & -0.039 \\
\hline spelling phono & 0.514 & 0.087 & 5.878 & $<.001 * *$ & 0.479 & 0.514 & 0.087 & 5.878 & $<.001 * *$ & 0.477 \\
\hline spelling speed & 0.374 & 0.498 & 0.750 & .453 & 0.049 & 0.374 & 0.498 & 0.750 & .453 & 0.051 \\
\hline $\begin{array}{l}\text { spelling executive } \\
R^{2} \\
\text { Maths }\end{array}$ & $\begin{array}{c}-0.014 \\
.249\end{array}$ & 0.178 & $\begin{array}{c}- \\
0.081\end{array}$ & .935 & -0.009 & $\begin{array}{c}-0.014 \\
.248\end{array}$ & 0.178 & $\begin{array}{c}- \\
0.081\end{array}$ & .935 & -0.009 \\
\hline maths phono & 0.046 & 0.092 & 0.499 & .618 & 0.035 & 0.046 & 0.092 & 0.499 & .618 & 0.035 \\
\hline maths speed & -0.019 & 0.567 & 0.034 & .973 & -0.002 & -0.019 & 0.567 & $\begin{array}{c}- \\
0.034\end{array}$ & .973 & -0.002 \\
\hline $\begin{array}{l}\text { maths } \sim \text { executive } \\
R^{2} \\
\text { Vocab }\end{array}$ & $\begin{array}{c}1.189 \\
.392\end{array}$ & 0.202 & 5.903 & $<.001 * *$ & 0.597 & $\begin{array}{c}1.189 \\
.390\end{array}$ & 0.202 & 5.903 & $<.001 * *$ & 0.596 \\
\hline vocab phono & 0.236 & 0.096 & 2.471 & $.013 *$ & 0.185 & 0.236 & 0.096 & 2.471 & $.013 *$ & 0.202 \\
\hline vocab speed & -0.46 & 0.582 & $\begin{array}{c}- \\
0.791\end{array}$ & .429 & -0.051 & -0.46 & 0.582 & $\begin{array}{c}- \\
0.791\end{array}$ & .429 & -0.058 \\
\hline $\begin{array}{l}\text { vocab executive } \\
R^{2}\end{array}$ & $\begin{array}{c}0.847 \\
.322 \\
\end{array}$ & 0.210 & 4.039 & $<.001 * *$ & 0.435 & $\begin{array}{c}0.847 \\
.375 \\
\end{array}$ & 0.210 & 4.039 & $<.001 * *$ & 0.474 \\
\hline
\end{tabular}


Note. $\mathrm{p}<.05^{*} ; \mathrm{p}<.01 * *$, Estimates are from the constrained models. In all cases, constraining the paths did not significantly degrade the model fit. Phono=phonological processing; Vocab $=$ Vocabulary. 